\title{
RELATIONSHIP-CONTINGENT SELF-ESTEEM AS A MODERATOR OF BORDERLINE PERSONALITY FEATURES AND MATE RETENTION
}

\author{
A Thesis \\ By \\ SIERRA M. RUFINO \\ Submitted to the School of Graduate Studies \\ at Appalachian State University \\ in partial fulfillment of the requirements for the degree of \\ Master of Arts
}

May 2020

Department of Psychology 
RELATIONSHIP-CONTINGENT SELF-ESTEEM AS A MODERATOR OF

BORDERLINE PERSONALITY FEATURES AND MATE RETENTION

\author{
A Thesis \\ By \\ SIERRA M. RUFINO \\ MAY 2020
}

\title{
APPROVED BY:
}

Christopher J. Holden

Chairperson, Thesis Committee

Doris Bazzini

Member, Thesis Committee

Jacqueline Hersh

Member, Thesis Committee

Rose Mary Webb

Chairperson, Department of Psychology

Mike McKenzie, Ph.D.

Dean, Cratis D. Williams School of Graduate Studies 
Copyright by Sierra Rufino 2020

All Rights Reserved 


\author{
Abstract \\ RELATIONSHIP-CONTINGENT SELF-ESTEEM AS A MODERATOR OF \\ BORDERLINE PERSONALITY FEATURES AND MATE RETENTION \\ Sierra M. Rufino \\ B.S., University of North Carolina at Greensboro \\ Chairperson: Christopher J. Holden
}

The current study examined the relationship between borderline personality features, relationship-contingent self-esteem, and mate retention behaviors. Participants $(N=204)$ were recruited through Amazon's Mechanical Turk (MTurk). They completed the Personality Inventory for the DSM-5, the Rosenberg Self-Esteem Scale, the Relationship-Contingent SelfEsteem Scale, and the Mate Retention Inventory-Short Form. Participants then received feedback through the modified Future Alone Manipulation, where they were randomly assigned to one of three feedback conditions: positive, negative, or negative control. After the feedback, participants completed the Mate Retention Inventory-Short Form to assess their response to feedback. Contrary to our predictions, borderline personality features (BPF) were not correlated with relationship-contingent self-esteem (RCSE), and RCSE and threat did not moderate the relationship between BPF and mate retention behaviors (MRB). Consistent with our hypotheses, BPF predicted the used of cost-inflicting MRB. Interestingly, RCSE predicted the use of benefitprovisioning MRB. This research is the first to address the relationship between BPF and RCSE and provides insight into individuals differences in relationship behaviors. 


\section{Acknowledgements}

I want to thank my supervisor, Christopher J. Holden, for his patience, motivation, enthusiasm, and guidance. He gave me the opportunity to conduct research and gain invaluable experience to aid me in my journey towards earning a doctoral degree in psychology. I wish to extend my thanks to my committee members for help encouragement and insightful comments.

I thank my fellow classmates in the experimental psychology masters' program: Sidney L. Murray, James B. Wyngaarden III, Elijah J. Richardson, Olivia M. Godfrey, Victor L. Norris III, Jessica M. Chambers, Katherine G. Quinn, Zachery A. Mondlak, and Michael T. Spencer. They have been extremely supportive, resourceful, and helpful through my time as a master's student at Appalachian State University. I have truly enjoyed my time with them, as they made every day fun for me.

Furthermore, I want to thank the Office of Student Research at Appalachian State University for funding my research project. Furthermore, I wish to thank Appalachian State University for funding any traveling needed to present my research through the Wiley F. Smith Endowment Award, the College of Arts and Sciences Student and Faculty Excellence Fund, and the GSAS Research Presentation Travel Award.

Last but not least, I would like to thank my family for all of their support throughout my academic career. 


\section{Dedication}

I dedicate my thesis to my family and friends, who have always been supportive in my academic interests and push me to be motivated and successful. 


\section{Table of Contents}

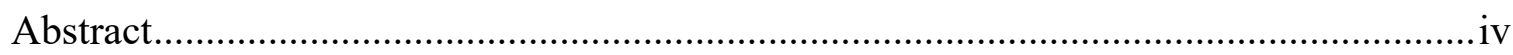

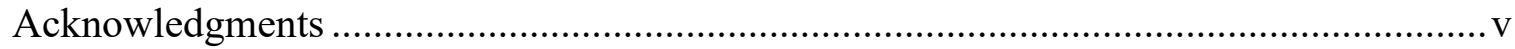

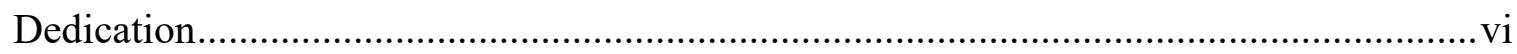

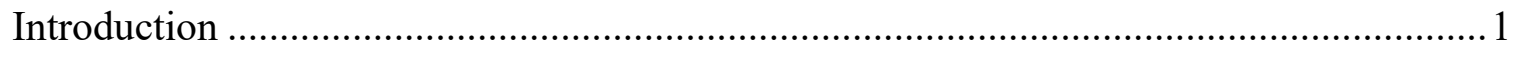

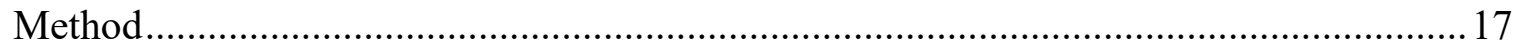

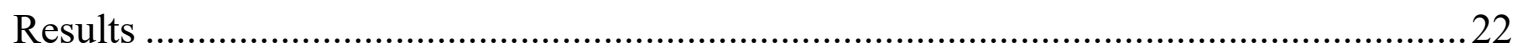

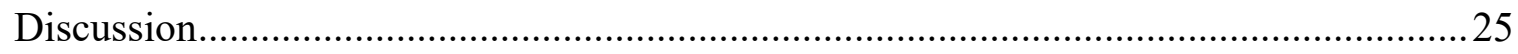

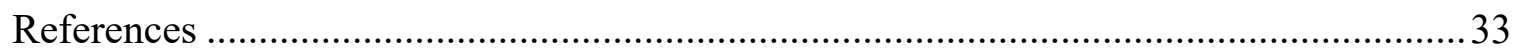

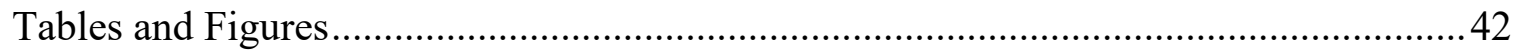

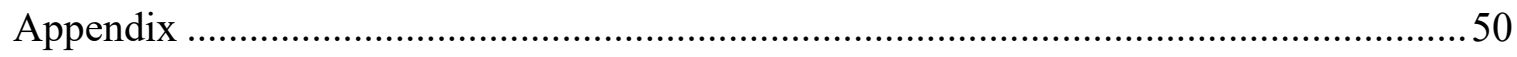

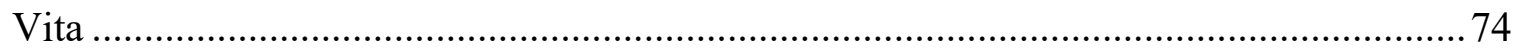




\section{Introduction}

Borderline personality disorder (BPD) is prevalent in approximately $1.6 \%$ of the population but, it is estimated that this disorder could be as common as $5.9 \%$ of the population or higher due to the number of individuals that never seek therapy or receive a diagnosis (American Psychiatric Association [APA], 2013). Furthermore, only a quarter of diagnosed individuals are male, meaning that this disorder is predominantly prevalent among the female population (APA, 2013). While the developmental course of this disorder varies, it typically begins to crystallize in early adulthood as shown by chronic instability in relationships. However, the majority of individuals with BPD develop stability in relationships around their 30s to 40s (APA, 2013). There are nine symptoms that define BPD. Some of these symptoms are more prominent and representative of the disorder, as they are commonly referred to as key criteria.

BPD is primarily characterized by an intensely strong fear of abandonment (criterion 1; APA, 2013). Individuals with BPD will frantically attempt to avoid any perceived abandonment by engaging in a range of behaviors, such as seeking new or maintaining current relationships (APA, 2013). In turn, those diagnosed with BPD develop high levels of rejection sensitivity. However, despite their attempts to avoid loneliness, they are often unable to maintain stable relationships (APA, 2013; Rosenthal et al., 2008).

Interpersonal relationship instability, listed as the second criterion, is another defining feature of BPD (APA, 2013). This pattern of instability derives from several factors. For instance, when meeting new potential romantic or nonromantic partners, individuals with BPD often "skip" the initial stage of the relationship, the acquaintance stage, and immediately share intimate details (APA, 2013). Additionally, individuals with BPD show nurturing characteristics; however, this may occur with the belief that they will be rewarded with those same 
characteristics from their partner (APA, 2013). Finally, individuals with BPD show fluctuations in the way they view and treat their romantic partners. One moment, they may view their partner with admiration, but they can later devalue them (APA, 2013). This may be further precipitated by an unstable sense of self, which is associated with changes in identity, such as self-esteem, sexual identity, career goals, and feelings of belonging (criterion 3; APA, 2013).

Individuals with BPD tend to impulsively engage in self-damaging behaviors (criterion 4) when they perceive rejection or abandonment (APA, 2013). Common self-damaging behaviors include gambling, binge eating or drinking, risky sexual behaviors, and reckless driving (APA, 2013). In addition to marked impulsivity, individuals with BPD often exhibit suicidal tendencies (criterion 5; APA, 2013). Approximately 8\%-10\% of individuals diagnosed with BPD have completed suicide, and a higher percentage have attempted suicide or engaged in self-mutilating behaviors (APA, 2013).

This sixth criterion of BPD is emotion dysregulation. As a result, individuals with BPD may respond with heightened negative emotional responses to rejection, perceived threat, or other emotional stimuli that may result in perceived loneliness (Rosenthal et al., 2008). In addition to the tendency to experience intense levels of negative affect, individuals with BPD often report feelings of emptiness (criterion 7) and struggle to control feelings of anger (criterion 8; APA, 2013). As such, individuals with BPD may respond aggressively, whether it be verbally or physically. Finally, individuals with BPD may experience dissociative symptoms or paranoid ideation towards others when experiencing extreme stress due to perceived abandonment (criterion 9; APA, 2013).

In conclusion, BPD is characterized by instability in interpersonal relationships, selfidentity, and affect, as well as marked impulsivity. Furthermore, the fear of abandonment also 
serves as a trigger for individuals with BPD, as the perception of rejection or abandonment leads to the onset of some of the maladaptive and impulsive symptoms associated with BPD (APA, 2013). Because of an increased risk of individuals with BPD to commit suicide or engage in selfharming tendencies in response to negative relationship events, the need to research and understand interpersonal functioning for individuals with BPD is necessary to improve treatment and decrease suicide rates among this population. Specifically, the current study examined BPD and functioning in romantic relationships because research has found that individuals with BPD are more sensitive to, and react more intensely, to events in their romantic relationships compared to other interpersonal relationships, suggesting that individuals with BPD value romantic relationships more than any other type of interpersonal relationship (Lazarus et al., 2018).

\section{A Dimensional Approach to Borderline personality disorder}

The current edition of the DSM-5 follows a categorical approach to diagnosing personality disorders (APA, 2013). For BPD, an individual must exhibit five out of the nine listed symptoms to receive a diagnosis (APA, 2013). However, this approach to measuring BPD has been criticized because it fails to consider that many individuals that suffer from borderline personality symptoms are unable to meet the requirements to be diagnosed with and treated for this disorder. Therefore, it has been suggested that personality should be conceptualized dimensionally using a spectrum that ranges from typical to maladaptive personality traits, as this is highly beneficial to further capture the nature of BPD (Widiger, 2011; Widiger \& Trull, 2011).

The DSM-5 has proposed an alternative model for measuring personality disorders (APA, 2013). In this model, BPD is measured dimensionally using five pathological personality traits that predict behaviors that align with BPD symptomology. The five pathological personality 
traits are antagonism, negative affectivity, detachment, disinhibition, and psychoticism. The Personality Inventory for the DSM-5 (PID-5) is a self-report questionnaire used to measure the personality traits under the alternative approach (Kruger, Derringer, Markon, Watson, \& Skodol, 2012). BPD can be primarily predicted by an increase in negative affectivity, antagonism, and disinhibition (APA, 2013). Further research suggests that BPD is positively associated with all five traits and most trait facets that are assessed by the PID-5 (Calvo et al., 2016).

As this is in line with how many other personality traits are measured, including some of those described below, it was decided that a dimensional approach to BPD would be used for the current study. In turn, borderline personality features (BPF) was be measured across the traits described in the PID-5. As a result, it was not necessary for this study to measure individuals with clinical diagnoses. Instead, a nonclinical sample was examined, meaning that we recruited a standard population and not individuals diagnosed with BPD. We assessed how variability in the five traits of the PID-5 is associated with differences in relationship behavior.

\section{Romantic Relationships}

Humans are social beings driven by their need to belong (Baumeister \& Leary, 1995). Relationships that satisfy this need are long-lasting and caring, and they are characterized by enduring interpersonal attachments and positive interactions (Baumeister \& Leary, 1995). Obtaining satisfying interpersonal relationships fulfills the need to belong, which leads to positive affect for the individual (Baumeister \& Leary, 1995). Although this theory suggests that people satisfy the need to belong by seeking multiple social relationships, research has found that individuals reduce the number of social interactions with others when they begin a romantic relationship (Baumeister \& Leary, 1995; Milardo, Johnson, \& Huston, 1983). This suggests that romantic relationships, compared to other interpersonal relationships, are uniquely effective in 
satisfying the need to belong. However, it is found that any type of interpersonal relationship has poor quality if it does not satisfy the need to belong. As a result, people will possibly abandon that relationship to seek other relationships (Baumeister \& Leary, 1995; Berman, 1988).

Many other factors influence the quality of romantic relationships. Murray (2005) noted that satisfying relationships must be secure, such that individuals must believe that their partner views them positively and that rejection is unlikely (Murray, Holmes, \& Griffin, 2000; Murray, 2005). The feeling of being irreplaceable, where an individual's qualities are not easily available among other potential partners, also creates a secure relationship (Murray et al., 2009). Furthermore, feeling accepted by one's partner is important because it increases relationship satisfaction by strengthening the connection between partners (Murray, Griffin, Rose, \& Bellavia, 2006). When a relationship fails to meet such characteristics, it cannot satisfy the need to belong and may result in rejection, dissolution, and cause negative affect (Baumeister \& Leary, 1995).

Research has shown that individuals with higher levels of BPF often report experiencing more troubled and unstable relationships, which may be exacerbated by BPD symptomology (e.g., Bouchard, Sabourin, Lussier, \& Villeneuve, 2009; Daley et al., 2000; Zeigler-Hill \& Abraham, 2006). For instance, BPD is positively associated with romantic dysfunction, which may contribute to lower-quality relationships being reported by those with BPD when compared to healthy couples (i.e. where both partners are not diagnosed with BPD; Daley, Burge, \& Hammen, 2000; Hill et al., 2011; Selby, Braithwaite, Joiner, \& Fincham, 2008). Specifically, BPD symptomology is positively correlated with the number of relationships for individuals with BPD and the frequency of romantic conflict within those relationships (Daley et al., 2000). Furthermore, a high percentage of couples, with at least one partner diagnosed with BPD, 
reported episodic relationship instability, where the couples repeatedly break up and get back together (Bouchard et al., 2009). Additionally, both partners within couples where one partner was diagnosed with BPD reported significantly lower relationship satisfaction compared to healthy couples (Bouchard et al., 2009; Daley et al., 2000). Thus, it seems that individuals with higher levels of BPF experience more troubled relationships compared to healthy relationships. However, it may be that there are other personality traits associated with BPD that precipitate negative experiences within troubled relationships.

\section{Self-Esteem in the Context of Romantic Relationships}

Self-esteem is a trait that plays a major role in interpersonal functioning, as it is positively associated with relationship satisfaction (e.g., Murray, Holmes, \& Griffin, 1996; Murray et al., 2000). For instance, feelings of acceptance, a factor associated with greater relationship success, is much lower for individuals with low self-esteem compared to individuals with high-selfesteem (Murray et al., 2006). Additionally, individuals with low self-esteem may project their own self-doubts onto their partner and the relationship that they have with them. In turn, this can diminish the felt security of the relationship (Murray, 2005; Murray, Holmes, MacDonald, \& Ellsworth, 1998). For example, if an individual with low self-esteem feels as though their partner views them negatively, they may perceive an increased likelihood of rejection. If experienced over time, they may also begin to over-perceive such rejection and respond in ways that serve to protect from such rejection (e.g., Murray et al., 2000; Murray, 2005). Furthermore, those with low self-esteem may feel that they are easily replaceable. This could decrease the amount of trust between partners and could add to their desire to avoid further investment in the relationship in order to protect their self-esteem (Murray et al., 2009). Taken together, these findings suggest that the romantic relationships for individuals with low self-esteem may be characterized by poor 
security, trust, and acceptance; all of which are associated with poorer relationship satisfaction (Murray, 2005; Murray et al., 2006; Murray et al., 2009)

Adding to this is the negative correlation between self-esteem and BPD, which may further explain why relationships for a person with BPD are typically troubled and unsatisfying in nature (Zeigler-Hill, 2013; Zeigler-Hill \& Abraham, 2006). This suggests that while it is important to investigate self-esteem in the context of romantic relationships, it would be beneficial to consider self-esteem and BPF together in the context of romantic relationships. However, no research has done so. That being said, it has been found that self-esteem is positively correlated with relationship satisfaction, whereas BPD is negatively associated with relationship satisfaction (Bouchard et al., 2009; Daley et al., 2000; Murray et al., 1996; Murray et al., 2000). Thus, it may be that self-esteem and BPD symptoms interact with each other to shape romantic relationships. Therefore, analyzing the relationship between self-esteem and BPF could provide further insight into the nature of relationships for people with BPD.

\section{Contingent Self-Esteem}

Although it can be insightful to investigate differences between people of high and low self-esteem, recent research has suggested that self-esteem is multi-faceted, and there may be a number of ways in which people derive their feelings of self-worth (Kernis, 2003). In turn, an important factor to consider in understanding the nature of self-esteem is whether self-esteem is contingent (Crocker \& Wolfe, 2001). Contingent self-esteem occurs when an individual's selfworth depends on their successes or failures in a specific domain of life (Crocker \& Wolfe, 2001). Individuals with contingent-self-esteem often have a strong goal of validating themselves and their abilities related to the domain of contingency (Crocker \& Park, 2004). Furthermore, as contingent individuals experience successes and failures, their self-esteem level fluctuates 
(Crocker \& Wolfe, 2001). For instance, academic-contingent self-esteem would occur when someone derives their self-worth from their academic success. As a result, receiving a failing grade would lead to a decrease in their self-esteem, whereas a high grade would do the opposite (Crocker, Karpinski, Quinn, \& Chase, 2003).

Crocker and Wolfe (2001) suggested that there are a variety of domains of contingent self-esteem, and people may vary in their degree of contingency. Some of these domains include personal appearance, others' approval, academics, or religiosity (Crocker \& Wolfe, 2001). However, contingent self-esteem is not limited by these originally proposed domains. As research continues, other domains are being discovered. Beard and Wickham (2016) found that individuals' self-worth can be determined through performance in video games. Competitive card games may also serve as a type of contingency (Megeau, Carpentier, \& Vallerand, 2011). Contingencies can also involve interpersonal relationships (Crocker \& Wolfe, 2001; Knee, Canevello, Bush, \& Cook, 2008). For example, individuals can base their self-worth on the relationship that they have with their family or friends (Cambron, Acitelli, \& Steinberg, 2010; Crocker \& Wolfe, 2001). Possibly of greater importance for BPD, it has also been proposed that some individuals derive their feelings of self-worth from their romantic relationships (Knee, Canevello, Bush, \& Cook, 2008).

\section{Relationship-Contingent Self-Esteem}

Individuals who derive their feelings of self-worth from their romantic relationships are said to have relationship-contingent self-esteem (RCSE; Knee et al., 2008). Individuals with high levels of RCSE base their self-worth on whether they are in a romantic relationship and the nature of their relationship (Knee et al., 2008). Thus, they may be particularly focused on factors such as commitment and satisfaction (Knee et al., 2008). In turn, individuals with high levels of 
RCSE report high self-esteem when they are in a romantic relationship (Sanchez \& Kwang, 2007). Thus, their relationships are directly influencing their evaluations of themselves.

Relationship-contingent self-esteem may impact other behaviors surrounding the romantic relationship. For example, those with high levels of RCSE are more likely to engage in drinking alcohol as a method to cope with negative relationship events or low relationship satisfaction, and this may be more prevalent in men than women (DiBello, Rodriguez, Hadden, \& Neighbors, 2015; Rodriguez, Knee, \& Neighbors, 2014). There are also unique effects for women, such that those with higher levels of RCSE have greater sexual motives, suggesting that women are more likely to engage in sex to improve relationship quality (Sanchez, Moss-Racusin, Phelan, \& Crocker, 2011). Thus, negative relationship events may influence the likelihood that individuals with high levels of RCSE may engage in harmful or risky behaviors.

The dissolution of a relationship may be particularly impactful for individuals with high levels of RCSE. For example, they have been found to engage in obsessive pursuit following a breakup and report more emotional distress after a breakup (Park, Sanchez, \& Brynildsen, 2011). Similarly, individuals with BPD respond to the perception of negative relationship events with extreme distress (APA, 2013). Furthermore, they engage in impulsive and self-harming behaviors, suggesting that there are similarities between individuals with BPD and individuals with RCSE.

\section{Self-Esteem, BPD, and Relationship Functioning}

Although no research has addressed the relationship between RCSE and BPD, they seem to be similar in nature. For instance, studies have shown that self-esteem fluctuates for those diagnosed with BPD when they perceive negative relationship events (APA, 2013). These changes in self-esteem are also found among individuals with RCSE (Knee et al., 2008). Thus, 
individuals with BPD may be staking their feelings of self-worth on successes and failures within the relationship (i.e., they may have high levels of RCSE). Furthermore, understanding the relationship between RCSE and BPD may explain why those with BPD typically engage in maladaptive behaviors or respond with extreme negative affect after perceiving negative relationship events (APA, 2013; DiBello et al., 2015; Rodriguez et al., 2014; Park et al., 2011). Thus, RCSE may be present among individuals with BPD and interact with BPD symptoms to influence interpersonal functioning.

The presence of RCSE among individuals with BPD may help to further explain why they fear abandonment, as it would be detrimental to their self-esteem. In turn, they openly seek relationships and may interpret relationships as more intimate than they are in nature. For instance, individuals diagnosed with BPD often share personal and intimate details about their lives to individuals with whom they have only recently been acquainted with (APA, 2013). Because those with BPD tend to have a strong fear of loneliness, they are motivated to develop new interpersonal relationships, but they have a higher level of motivation to retain any current relationships in order to avoid abandonment. As a result, they may attempt to invest as much as they can within their romantic relationship to retain their partner and make the relationship last.

\section{Mate Retention}

While relationships are desired, they require effort and may not always be successful. Many situations arise that could lead to dissolution. One key factor that may lead to relationship dissolution is infidelity (Betzing, 1989). Furthermore, people may feel jealous when they perceive any threat in their relationship (Davis, Desrochers, DiFilippo, Vaillancourt, \& Arnocky, 2018). Jealousy may serve as motivation to protect or preserve one's relationship (Davis et al., 2018). In turn, there may be specific behaviors that follow jealousy and serve to maintain the 
relationship. Mate retention behaviors $(\mathrm{MRB})$ are argued to serve this purpose. There are a number of strategies and tactics that range from "vigilance to violence" (Buss, 1988, p. 291). Although varied, these behavioral strategies and tactics serve the two broad goals of ensuring continued investment and preventing defection.

These goals are reflected in the two large domains of benefit-provisioning and costinflicting mate retention behaviors (Buss, 1988; Buss \& Shackelford, 1997; Miner, Starratt, \& Shackelford, 2009; Shackelford, Goetz, \& Buss, 2005). Benefit-provisioning behaviors encompass things such as displaying love, improving one's appearance, complementing the partner, and buying them gifts. In turn, they function to incentivize continued investment in the relationship (Shackelford et al., 2005; Miner et al., 2009). In contrast, cost-inflicting behaviors include things such as violent threats, manipulation, monopolization of free time, and derogation of rivals. These behaviors, in turn, make partners feel that it may be unwise or risky to end the relationship; therefore, they are more likely to remain in the relationship to prevent such risks (Shackelford et al., 2005; Miner et al., 2009).

Mate retention behaviors also influence the quality of romantic relationships. Salkicevic, Stanic, and Grabovac (2014) measured the relationship between relationship satisfaction and mate retention behaviors. Benefit-provisioning mate retention behaviors were positively correlated with relationship satisfaction, but cost-inflicting mate retention behaviors were negatively correlated with relationship satisfaction (Salkicevic et al., 2014). Additionally, spouses reported less marital satisfaction when their partners engaged in mate guarding, a facet of cost-inflicting mate retention behaviors, such as monopolization of spouse's time, emotional manipulation, and threatening or punishing infidelity (Shackelford \& Buss, 2000). This further suggests that the use of cost-inflicting mate retention behaviors is associated with lower 
relationship satisfaction. In turn, it becomes important to understand who might use which mate retention behaviors.

\section{Individual Differences in the Use of Mate Retention Behaviors}

Men and women often use different mate retention behaviors (Buss, 1988). Women often use appearance enhancement or jealousy induction, and men frequently use resource display or concealment of mate (Buss, 1988). Further research has found that newlywed husbands were more likely to use mate retention behaviors such as resource display and submission and debasement (i.e. willingly giving in or following a partner's wishes or demands), while newlywed wives were more likely to use appearance enhancement tactics (Kaighobadi, Shackelford, \& Buss, 2010). Additionally, women are more inclined to use benefit-provisioning and cost-inflicting mate retention behaviors after experiencing feelings of reactive jealousy (i.e., feelings of jealousy that arise in cases where one's partner may have been unfaithful; Davis et al., 2018). In contrast, men were less inclined to use either type of mate retention behavior when experiencing feelings of reactive jealousy. Additionally, men were found to report experiencing much lower levels of reactive jealousy when compared to women (Davis et al., 2018).

Additionally, individual differences among self-esteem may influence one's motivation to engage in behaviors to protect relationships. Specifically, self-esteem is negatively correlated with the use of cost-inflicting behaviors (Holden, Zeigler-Hill, Shackelford, \& Welling, 2018). Thus, people may be less inclined to engage in cost-inflicting behaviors when they have high levels of self-esteem, as they are typically more focused on engaging in benefit-provisioning mate retention behaviors. In contrast, individuals with high levels of RCSE should be more inclined to use a wider array of mate retention behaviors because they should be highly motivated to retain their current partner, as it ensures that their self-esteem will not be damaged 
or significantly drop. Indeed, RCSE is positively associated with both benefit-provisioning and cost-inflicting behaviors, supporting the notion that RCSE is associated with high levels of motivation to maintain relationships (Holden et al., 2018).

Research has examined the relationship between other personality traits and the use of mate retention behaviors. For instance, individuals with low levels of agreeableness are more likely to use cost-inflicting mate retention behaviors (de Miguel \& Buss, 2011). In contrast, there is a positive association between the use of benefit-provisioning mate retention and agreeableness in males (McKibbin, Miner, Shackelford, Ehrke, \& Weekes-Shackelford, 2014). Those high in neuroticism are more inclined to engage in both cost-inflicting and benefitprovisioning mate retention (de Miguel \& Buss, 2011; McKibbin et al., 2014). Higher levels of conscientiousness and openness to experience are negatively associated with the use of costinflicting mate retention behaviors (Atari, Barbaro, Sela, Shackelford, \& Chegeni, 2017). Previous research suggests that BPD is positively correlated with neuroticism, but negatively correlated with agreeableness and conscientiousness (Clarkin, Hull, Cantor, \& Sanderson, 1993). This suggests that those with BPD may be more likely to use cost-inflicting mate retention behaviors.

This is further supported by the fact that connections have been found between mate retention behaviors and the pathological personality features measured by the PID-5 (Holden, Roof, McCabe, \& Zeigler-Hill, 2015). A positive relationship has been found between antagonism and the use of both benefit-provisioning and cost-inflicting mate retention behaviors because individuals with high levels of antagonism are willing to use any strategy necessary to retain long-term partners in order to stay in a relationship that they have spent a considerable amount of time investing in to ensure that such time was not wasted. However, they are more 
inclined to engage in cost-inflicting mate retention behaviors, such as emotional manipulation, because they are often manipulative and deceitful towards others and exhibit grandiose behaviors. Similarly, negative affectivity was positively associated with benefit-provisioning and cost-inflicting behaviors because, like individuals with high levels of antagonism, individuals with high levels of negative affectivity will do whatever they can to prevent their partner from either leaving the relationship or engaging in infidelity (Holden et al., 2015). If BPD is positively associated with all five domains (i.e. negative affectivity, detachment, antagonism, disinhibition, and psychoticism), then the connection between BPD, the PID-5, and mate retention behaviors provides further evidence that BPD may be associated with cost-inflicting mate retention behaviors (Calvo et al., 2016; Holden et al., 2015).

There are relatively few studies that have directly examined the association between mate retention and BPD. Centifanti, Thomson, and Kwok (2016) examined the relationship between psychopathic traits, BPD, and mate retention strategies. BPD was positively associated with the general use of mate retention strategies (Centifanti et al., 2016). Further research has shown that there is a strong, positive association between borderline personality features and the use of costinflicting mate retention behaviors (Tragesser \& Benfield, 2012). Among men, borderline personality features were positively correlated with cost-inflicting behaviors such as emotional manipulation, violence against rivals, monopolization of time, and commitment manipulation (i.e. demanding a partner to openly express their willingness to commit to the relationship). Borderline personality features among women were positively related to cost-inflicting behaviors such as jealousy induction, derogation of competitors, and derogation of mate. Both men and women with higher borderline personality features were more likely to engage in vigilance, intersexual threats, and punish mate's infidelity threats. Such research provides direct evidence 
that those with BPD may be inclined to use cost-inflicting mate retention behaviors.

However, Tragesser and Benfield (2012) also found that men and women with higher borderline personality traits engage in more sexual inducements (i.e. using sex to further develop the relationship or to keep one's partner from leaving the relationship) than those with lower levels of borderline personality traits. While this tactic is considered a benefit-provisioning mate retention behavior, Tragesser and Benfield (2012) argued that those with BPD may engage in sexual inducements as a maladaptive mate retention tactic, and it may be harmful to the relationship. This contradicts the findings that benefit-provisioning mate retention behaviors are positively associated with relationship satisfaction (Salkicevic et al., 2014). It was noted that individuals with BPD may be more inclined to use certain cost-inflicting behaviors and sexual inducements due to their impulsive tendencies to engage in self-harming behaviors (e.g. sexual behaviors, substance misuse, etc.), which typically arise in response to negative relationship events (APA, 2013; Tragesser \& Benfield, 2012). In other words, these impulsive behaviors may lead to the use of potentially harmful mate retention tactics (Tragesser \& Benfield, 2012).

In conclusion, evidence suggests that individuals with higher levels of BPF may be more inclined to use cost-inflicting mate retention behaviors (Atari et al., 2017; Calvo et al., 2016; Clarkin et al., 1993; de Miguel \& Buss, 2011; Holden et al., 2015; McKibbin et al., 2014; Tragesser \& Benfield, 2012). Furthermore, it is important to understand the influence of impulsivity due to perceived relationship threat on the relationship between BPD, RCSE, and the use of mate retention behaviors because it may predict, in addition to BPF and RCSE, the use of cost-inflicting mate retention behaviors (Holden et al., 2018; Tragesser \& Benfield, 2012).

\section{Current Study}

The relationship between RCSE and BPF has yet to be addressed in the literature. This 
study attempted to answer a unique question about interpersonal functioning for individuals with high levels of BPF. Previous research has suggested that individuals with BPD or high levels of RCSE are similar in that they respond similarly to perceived negative relationship events. Therefore, it can be predicted that there is an association between BPF and RCSE. However, it is yet to be determined exactly how these traits might come together. Thus, the current study measured the relationship between borderline personality features, relationship-contingent selfesteem, and mate retention behaviors. Because BPF and RCSE exhibit similar characteristics, and they both are positively associated with the use of cost-inflicting behaviors (Tragesser \& Benfield, 2012; Holden et al., 2018), it was predicted that RCSE would significantly moderate the relationship between BPF and cost-inflicting MRB. By examining RCSE as a moderator, we were able to potentially explain why individuals with high levels of BPF are motivated to engage in cost-inflicting mate retention behaviors. Therefore, it was hypothesized that 1) BPF would positively predict the use of cost-inflicting MRB, and 2) RCSE would be positively associated with BPF, and 3) individuals with higher levels of BPF, who also have higher levels of RCSE, would be more inclined to engage in cost-inflicting mate retention behaviors.

Furthermore, this relationship was measured under a manipulated relationship threat. As previously stated, those diagnosed with BPD are hypersensitive to relationship threat due to their fear of abandonment and affect instability (APA, 2013). The perception of relationship threat often triggers them to engage in impulsive and maladaptive behaviors. It has been suggested that individuals with higher levels of BPF may be more inclined to engage in the use of costinflicting behaviors as an impulsive response to negative relationship events (Tragesser \& Benfield, 2012). Thus, the purpose of including relationship threat was to examine if the perception of threat increases one's willingness to engage in mate retention behaviors. It was 
predicted that there will be a three-way interaction between BPF, RCSE, and threat when analyzing the use of cost-inflicting mate retention behaviors. As such, individuals higher in BPF, who also have high levels of RCSE, would show a greater willingness to engage in costinflicting MRB when exposed to relationship threat compared to individuals with lower BPF or individuals with higher BPF who are not exposed to a relationship threat.

\section{Method}

\section{Participants}

To determine the proper sample size needed for this study, an a priori power analysis was conducted in $\mathrm{G}^{*}$ Power for a multiple linear regression (Faul, Erdfelder, Buchner, \& Lang, 2009). Assuming an effect size of $f^{2}=0.15$ and seven predictors (BPF, RCSE, threat, their two-way interactions, and their three-way interaction), a sample size of 153 participants was needed to produce power at the .95 level. However, G*Power may have underestimated the sample size needed for our regression model. To account for such error and possible participant attrition, the planned sample size was increased to 350 participants.

Ultimately, two-hundred and four participants $($ Female $=121$, Male $=121)$ were recruited through Amazon's Mechanical Turk (MTurk) and paid \$3.75 upon completion of the study. Recruiting ended due to financial restrictions. However, MTurk has been shown to be a suitable platform for collecting data on personality disorders (Miller, Crowe, Weiss, Maples-Keller, \& Lynam, 2017). To be eligible, participants were required to be 18 years of age or older because BPD does not begin to crystallize until about early adulthood (APA, 2013).

The average age of the participants was $36.93(S D=10.41)$ years, and ages ranged from 21 to 70 years of age. The majority of participants self-identified as white $(n=157)$, and the remaining participants identified as African American $(n=17)$, Hispanic or Latino $(n=16)$, 
Asian American $(n=9)$, American Indian or Alaskan Native $(n=1)$, or other $(n=4)$. The average relationship length was 90.62 months $(S D=96.84)$, where 187 participants were in a relationship and 20 individuals were single. Two participants reported they were unsure of their relationship status. The average level of BPF was $0.83(S D=0.46)$, and scores ranged from 0.07 to 2.20 . It is suggested that an average score above 2.00 indicates a significantly high level of a given personality trait or amalgam of traits (Calvo et al., 2016). Three participants scored above 2.00, suggesting that they may meet the requirements for a diagnosis for BPD (Calvo et al., 2016). The average level of RCSE was $3.60(S D=0.83)$. Scores ranged from 1.10 to 5.00. For self-esteem, the average score was $3.73(S D=0.98)$.

\section{Materials}

Borderline Personality Features. BPF was measured using the Personality Inventory for the DSM-5 (PID-5; Krueger et al., 2012). The PID-5 is a 220-item questionnaire designed to measure personality traits that align with the personality disorders that are listed under cluster B of the DSM-5, where BPD falls (See Appendix C). Participants were asked to rate each item based on how accurately they find the statement to represent themselves. Participants rated each item using a 4-point frequency-scale ranging from 0 (very false or often false) to 3 (very true or often true). The PID-5 measures five dimensions: negative affect ( $\alpha=.94$; e.g., "I dread being without someone to love me"), detachment ( $\alpha=.96$; e.g., "I prefer to keep romance out of my life"), antagonism ( $\alpha=.94$; e.g., I'm good at making people do what I want them to do"), psychoticism ( $\alpha=.95$; e.g., "People often talk about me doing things I don't remember at all"), and disinhibition ( $\alpha=.89$; e.g., "I feel like I act totally on impulse"). Similar to previous research, the current study found that the PID-5 $(\alpha=.99)$ and each domain (negative affectivity: $\alpha=.95$; detachment: $\alpha=.94$; antagonism: $\alpha=.95$; disinhibition: $\alpha=.94$; and psychoticism: $\alpha=$ 
.97) to be highly reliable.

The PID-5 has been shown to adequately capture the dimensional diagnosis of BPD proposed in the DSM-5 (Calvo et al., 2016; Fowler et al., 2018). Research suggests that BPD has a significantly positive association with all five domains of the PID-5 and the PID-total score (Calvo et al., 2016). Thus, a total PID-score, which measures the presence of each trait within the individual, determined the degree of BPF prevalence. A higher total score on the PID-5 was indicative of higher BPF, while a lower score suggests that few BPF were present.

Relationship-Contingent Self-Esteem. RCSE was measured using the RelationshipContingent Self-Esteem Scale (RCSES; Knee et al., 2008). The RCSES is an 11-item self-report questionnaire (e.g., "When my relationship is going well, I feel better about myself overall") with a 5-point rating scale ranging from 1 (not at all like me) to 5 (very much like me). Participants responded to each item by rating how accurately each item describes themselves (See Appendix E). The RCSES was reliable in the current study $(\alpha=.90)$, which is consistent with previous research $(\alpha=.90 ;$ Knee et al., 2008).

Self-Esteem. Global self-esteem level was measured using the Rosenberg Self-Esteem Scale (RSES; Rosenberg, 1965). The RSES is a 10-item self-report questionnaire with a 5-point Likert scale ranging from 1 (strongly disagree) to 5 (strongly agree). Participants were asked to answer each item (e.g., "On the whole, I am satisfied with myself") based on how accurately it depicts themselves (See Appendix D). The reliability of the RSES in the current study was ( $\alpha=$ .93) greater than that of previous research $(\alpha=.88$; Blascovich $\&$ Tomaka, 1991).

The RSES was included as a measure of global self-esteem because contingent selfesteem drives these broader evaluations of self-esteem. For example, in individuals with RCSE, their feelings of self-esteem will be high when they perceive their relationship to be going well, 
but the opposite is true in cases where they see their relationship or their partner in a negative light. Typically, individuals with RCSE hold relatively negative evaluations of their relationships, and this is why we tend to see a negative correlation between RCSE and selfesteem (Holden et al., 2018). Furthermore, contingent self-esteem and global self-esteem may interact to predict certain outcomes. Thus, measuring global self-esteem allowed us to accurately capture RCSE and self-esteem levels, while also allowing for additional exploratory analyses.

Mate Retention Behaviors. MRB was measured using the Mate Retention InventoryShort Form (MRI-SF; Buss, Shackelford, \& McKibbin, 2008). The MRI-SF is a 38-item selfreport questionnaire that measures 19 mate retention tactics $(\alpha=.90)$. The tactics were grouped into two major types of mate retention behaviors: benefit-provisioning mate retention behaviors (16 items) and cost-inflicting behaviors (22 items; See Appendix F; Miner et al., 2009). Participants responded to each item based on the frequency of engaging in that behavior (e.g., “Complimented my partner on her appearance") using a 4-point frequency-scale ranging from 0 (never performed this act) to 3 (often performed this act).

The MRI-SF was administered twice as a pre-post measure for MRB to help us account for the changes in MRB following the different forms of feedback used. The MRI-SF was not designed as a pre-port measure. Thus, a pre-post measure was a relatively novel approach, but a previous study has used it in this manner (Holden et al., 2018). Each pre-post measure of MRB was more reliable in the current study (pre-cost-inflicting MRB: $\alpha=.93$; pre-benefitprovisioning MRB: $\alpha=.91$; post-cost-inflicting MRB: $\alpha=.94$; post-benefit-provisioning MRB: $\alpha=.93$ ) than in previous research (cost-inflicting MRB: $\alpha=.74$; benefit-provisioning MRB: $\alpha=$ .74; Miner et al., 2009).

Modified Future Alone Threat Manipulation. A modified Forecasting Rejection Task, 
also known as the future alone task, was used to induce relationship threat (Twenge, Baumeister, Tice, \& Stucke, 2001). This manipulation was suggested to be highly effective in inducing relationship threat for individuals with high levels of BPF because it directly targets the fear of abandonment, which plays a powerful role in how they react and respond to negative relationship events.

The original manipulation required participants to complete the Eysenck Personality Questionnaire (EPQ). Because the current study already utilized other personality measures, the EPQ was not included. Instead, participants would be notified that they would complete a series of questionnaires that address their personality and behaviors that occur within interpersonal settings (See Appendix G). Afterward, they were told that they may receive feedback based on their responses, but the feedback provided depended on the condition in which they were randomly assigned.

This manipulation comprised of three conditions: negative control, positive, and negative (see Appendix G). In the positive condition, participants received positive feedback that suggests that they would have a future of belonging in which they would have long-term relationship success. In the negative control condition, participants received negative feedback that addressed their accident-prone nature instead of their relationship success. The purpose of this condition was to control for the possibility that individuals may react to generally negative feedback rather than negative feedback regarding their relationship. Finally, participants in the negative condition received feedback that suggests that they were not compatible with long-term relationship success and would have a future in which they are alone.

\section{Procedure}

Participants completed the study online through MTurk. Before they began the study, 
they were presented a consent form (See Appendix G) where they were informed of the present study, the multiple self-report questionnaires that they would be asked to complete, and the feedback they would receive regarding their responses. Participants that agreed to participate in the study were asked to provide their consent by responding to a multiple-choice question in which they were able to choose between agreeing to consent and continuing with the study or disagreeing to provide their consent. At the beginning of the study, participants were asked to answer a series of questions that were followed by feedback (see Appendix I). They began the survey with demographic questions. Afterward, participants were administered, in a randomized order, the PID-5, RSES, RCSES, and the MRI-SF. Next, participants were randomly assigned to one of three conditions (positive, negative, or neutral) for the threat manipulation where they received feedback. A short prompt appeared on the screen to inform participants that their responses were being scored. After 30 seconds, participants received feedback regarding their personality. Participants were then given the MRI-SF once more. Throughout the study, attention checks were administered. Once participants completed the questionnaires, they were provided a debriefing form and thanked for participating in the study (See Appendix H). The debriefing form informed participants of the true nature of the study and clarified that the feedback prompts provided were false and not accurately representative of their personality. Furthermore, the debriefing form included resources for individuals who felt that they were negatively impacted by the study.

\section{Results}

Responses were collected from 233 participants. However, data from 28 participants were deleted due to large amounts of missing data (i.e., not responding to any questions in one or more given measures). One participant was removed after failing to successfully respond to at 
least two of the three attention checks. Borderline personality features were assessed using a total average score across all domains of the PID-5, where scores closer to 4 indicate higher levels of BPF. Self-esteem and RCSE were calculated via an average score across all items for each scale after the appropriate items were reversed coded. Cost-Inflicting MRB and benefit-provisioning MRB were calculated by creating an average frequency score across all relevant items.

To analyze the effects of the future alone manipulation, we dummy coded feedback conditions. Positive feedback was dummy coded with the following values: 0,1 . Negative feedback was set up as 0,0 . Finally, the values assigned to negative control feedback were 0,1 .

\section{Main Analyses}

A series of bivariate correlations were conducted to analyze the relationship between our main predictors and dependent variables (see Table 1). BPF was negatively correlated with selfesteem, $r=-.52, p<.001$, and positively correlated with cost-inflicting MRB, $r=.61, p<.001$, suggesting that individuals with BPD may exhibit low self-esteem and engage in more costinflicting MRB. RCSE was significantly negatively correlated with self-esteem, $r=-.18, p=$ .009 , and positively correlated with benefit-provisioning $\mathrm{MRB}, r=.47, p<.001$. Therefore, those that define their self-worth based on their romantic relationships have lower levels of global self-esteem and primarily engage in benefit-provisioning MRB. Self-esteem was negatively correlated with cost-inflicting MRB, $r=-.20, p=.004$. In turn, those that report lower levels of self-esteem engage in more cost-inflicting MRB. Finally, cost-inflicting MRB was positively correlated with benefit-provisioning MRB, $r=.49, p<.001$. Thus, people may be inclined to engage in one domain of MRB if they engage in the other domain of MRB.

A hierarchical regression was conducted to assess the three-way interaction between BPF, RCSE, and Threat on post-measures of cost-inflicting MRB (See Table 2). In the first 
block, BPF, RCSE, pre-measures of cost-inflicting MRB, and feedback condition were added as main effects. Furthermore, age, sex, and global self-esteem were included in the first block to serve as control variables. Additional correlations were conducted between our main variables of interest and our control variables (See Table 3). In the second block, the two-way interactions between BPF, RCSE, pre-measures of cost-inflicting, and feedback condition were entered. Finally, the third block consisted of three-way interactions between BPF, RCSE, pre-measures of cost-inflicting MRB, and feedback condition. The same model was used to assess the influence of the predictor variables on post-measures of benefit-provisioning MRB (See Table 2).

For cost-inflicting MRB, the first step was significant, $F(8,195)=252.06, p<.001, r^{2}=$ $.91, p<.001$. However, the pre-measure of cost inflicting MRB was the only significant main effect, $\beta=.92, t=33.24, p<.001$. Therefore, feedback did not predict MRB, and neither did BPF nor RCSE. This may be because pre-measures of cost-inflicting MRB accounted for all of the variance in the model, suggesting that there was little to no change between pre and post measures of MRB.

For benefit-provisioning MRB, the first model was significant, $F(8,195)=122.79, p<$ $.001, r^{2}=.83, p<.000$. There was a significant main effect of condition, $\beta=.07, t=2.09, p=$ .038 , where individuals exposed to the positive feedback condition reported an increase in benefit-provisioning MRB. There was also a significant main effect of pre-measures of benefitprovisioning $\mathrm{MRB}, \beta=.89, t=25.42, p<.001$. Therefore, our main predictor variables (i.e. BPF, RCSE, and Threat) did not account for any change in responding from pre-measures of MRB to post-measures of MRB. This suggests that there was little to no difference between our pre- and post-measures of benefit-provisioning and cost-inflicting MRB. No significant two-way or three-way interactions emerged for either regression models. 


\section{Additional Analyses}

Two separate linear regressions were conducted to assess the influence of BPF and RCSE regardless of feedback condition on cost-inflicting and benefit-provisioning MRB. BPF significantly predicted cost-inflicting $\mathrm{MRB}, \beta=.60, t=10.79, p<.001$, and accounted for approximately $4 \%$ of the variance, $F(2,201)=60.72, p<.001$ (See Table 4 ). Therefore, those that exhibit higher levels of BPF engage in more cost-inflicting MRB. In contrast, RCSE significantly predicted benefit-provisioning MRB, $\beta=.60, t=10.79, p<.001$, which accounted for approximately $2 \%$ of the variance, $F(2,201)=29.33, p<.001$ (See Table 4 ), showing that individuals with higher levels of RCSE reported using more benefit-provisioning MRB.

To break down the relationship between BPF, RCSE, and MRB, bivariate correlations were conducted to examine how BPF related to each individual mate retention tactic (see Table 5 and 6). These tactics are individual behaviors that exist below the broader domains of benefitprovisioning and cost-inflicting MRB. BPF was significantly correlated with three benefitprovisioning mate retention tactics: sexual inducements, $r(202)=.17, p=.017$, submission, $r(202)=.29, p<.001$, and possessive ornamentation, $r(202)=.18, p=.009$. RCSE was positively correlated with all eight benefit-provisioning mate retention tactics (see Table 5). BPF was positively correlated with all cost-inflicting mate retention tactics except for commitment manipulation (see Table 6). RCSE was positively correlated with three cost-inflicting tactics: monopolization of time, $r(202)=.15, p=.038$, emotion manipulation, $r(202)=.28, p<.001$, and commitment manipulation, $r(202)=.35, p<.001$ (See Table 6).

\section{Discussion}

The current study sought to examine how relationship-contingent self-esteem and relationship threat may impact the relationship between borderline personality features and mate 
retention. It was predicted that $\mathrm{BPF}, \mathrm{RCSE}$, and threat sensitivity would interact in a unique way to predict the use of cost-inflicting MRB. Specifically, we hypothesized that individuals with higher levels of BPF and RCSE will be most inclined to engage in cost-inflicting MRB after receiving negative feedback regarding their compatibility with successful, long-term relationships.

Inconsistent with our hypotheses, we did not find a significant three-way interaction. In other words, RCSE and threat did not moderate the relationship between BPF and Cost-inflicting MRB. Additionally, RCSE and BPF were not significantly correlated, suggesting that, while they may exhibit similar characteristics, they are two different constructs that predict different behaviors. Specifically, RCSE is a method of defining self-worth that may exist in varying degrees among the average, nonclinical population (Knee et al., 2008). Conversely, pathological personality traits, including BPF, are not commonly found among average populations. Furthermore, individuals with BPD are inclined to engage in cost-inflicting MRB, while individuals with RCSE are primarily inclined to engage in benefit-provisioning MRB to maintain their relationship (Knee et al., 2008; Holden et al., 2018; Tragesser \& Benfield, 2012).

Consequently, when simplifying our regression model to test the effects of BPF and RCSE on MRB, we found that BPF positively predicted cost-inflicting MRB, such that individuals were more willing to engage in cost-inflicting MRB if they exhibited higher levels of BPF. This is consistent with previous research by Tragesser and Benfield (2012), who suggested that individuals with BPD engage in cost-inflicting MRB as a function of impulsivity in maladaptive behaviors and a fear of abandonment. In addition, we found that borderline personality traits were positively correlated with all but one of the cost-inflicting tactics one could engage in towards their partner. Furthermore, BPF was positively correlated with sexual 
inducements, which is a tactic under benefit-provisioning MRB and replicates with previous research (Tragesser \& Benfield, 2012). Tragesser and Benfield (2012) argued that those with BPD engage in sexual inducements because sexual behaviors are common impulsive behaviors that those with BPD engage in and are often harmful to their relationships. In turn, this suggests that individuals with BPD are more inclined to engage in mate retention behaviors that may be harmful to their relationship and decrease relationship satisfaction (Salkicevic et al., 2014; Tragesser \& Benfield, 2012). This may partially explain why individuals with BPD experience unstable and unsatisfying romantic relationships (APA, 2013).

In contrast, we found that RCSE positively predicted benefit-provisioning MRB. People reported an increased willingness to engage in benefit-provisioning MRB if they reported higher levels of RCSE. RCSE was also positively correlated with all of the benefit-provisioning tactics. This is somewhat consistent with previous literature, as research has found that RCSE is associated with the use of both benefit-provisioning MRB and cost-inflicting MRB (Holden et al., 2018). However, the relationship between RCSE and cost-inflicting MRB has been inconsistent in previous research (Holden et al., 2018), which suggests that RCSE primarily predicts benefit-provisioning MRB and potentially explains the current findings. Holden and colleagues (2018) suggested individuals with high RCSE and self-esteem are likely to use benefit-provisioning MRB because they are highly motived to maintain their relationship and feel that their partner values them, and those with high self-esteem are less likely to use costinflicting MRB. On average, participants in the current study reported higher levels of selfesteem and RCSE. Thus, they may have been particularly motivated to use benefit-provisioning MRB (Holden et al., 2018).

Interestingly, we found that individuals were more willing to engage in benefit- 
provisioning MRB after receiving positive feedback. People are motivated to behave towards others in a manner that makes them feel accepted, as it is theorized that people feel the need to belong in their social groups and romantic relationships (Baumeister \& Leary, 1995). Thus, positive feedback may suggest that individuals are reinforced to engage in positive behaviors because they are told they are prone to successful relationships, which validates them and their relationship behaviors and fulfills their need to belong. However, positive feedback did not reinforce the use of cost-inflicting MRB. This may be because individuals who primarily use such behaviors are most likely experiencing dissatisfaction with their romantic relationship, as cost-inflicting MRB is negatively correlated with relationship satisfaction (Salkicevic et al., 2014). In turn, such feedback may not be salient for them, and, therefore, they may have been skeptical of the feedback or not motivated to continue using behaviors that maintain their relationship.

Additionally, no significant changes emerged after receiving negative feedback, meaning negative feedback did not impact either form of MRB. This is inconsistent with previous research that has used the future alone paradigm, as they found that negative feedback negatively impacts participants (e.g., Baumeister, DeWall, Ciarocco, \& Twenge, 2005; Twenge et al., 2001; Willis \& Nelson-Gray, 2017). To our knowledge, no research has found null effects for negative feedback. For cost-inflicting MRB, participants may not have found the feedback to be believable because it opposed their need to belong. In turn, individuals may have ignored the feedback or been in denial of the feedback's accuracy compared to positive feedback, whereas, in contrast, people are typically quick to attend to and accept praiseworthy information (i.e. positive feedback). Ability to engage in self-regulation may also impact one's response to negative feedback and use of mate retention behaviors. Research has suggested that people self- 
regulate their behaviors in order to be socially accepted in response to social rejection (Baumeister et al., 2005). For instance, people that experience rejection and show an improvement in self-regulation may adjust their behaviors to order to become socially accepted. However, such research has consistently found that rejection impairs self-regulation, as participants showed poorer performance in given tasks and were disinclined to make the effort to self-regulate (e.g., Baumeister et al., 2005). Thus, participants in the current study may have experienced impairment in their ability to self-regulate, leading to little change in reported desire to engage in cost-inflicting MRB.

The lack of significant changes in benefit-provisioning MRB may due to the notion that those that reported using such behaviors were most likely experiencing successful relationships, and negative feedback may not have been salient for those who had such relationships. Therefore, participants may have been skeptical of feedback, rendering the feedback useless in impacting MRB.

\section{Limitations and Future Directions}

Unfortunately, no study is without limitations. According to the power analyses, a sample size of 350 was needed to detect an effect size of $f^{2}=0.15$ in our complex model. However, due to restrictions in funding for participant compensation, we collected a total sample of 204 participants. Therefore, the study was underpowered, due to our complex model, and decreased the likelihood that we would detect a significant interaction if one truly is present. Nonetheless, our results still provided some insight into the relationship between borderline personality disorder and mate retention. Such research could be replicated using a larger sample size.

Furthermore, the current study was completed online by participants that are registered through MTurk. MTurk participants on average complete multiple surveys; therefore, they may 
have been previously exposed to the future alone manipulation or other surveys that include similar false feedback or rejection (Chandler, Mueller, \& Paolacci, 2014). In turn, they may have been suspicious of the feedback and how accurately it represented their personality.

Additionally, participants were only given one minute to read the feedback they were randomly assigned to receive before completing the rest of the study. One minute may not have been enough time for participants to properly digest the true meaning of the feedback nor dwell on such information and how it may impact their daily life. Some participants may also have shifted their attention away from the screen once learning they were unable to continue with the study immediately after receiving feedback. In turn, they may have been distracted and failed to properly process the feedback provided.

Moreover, the MRI-SF was designed to measure MRB that occurred within the previous year and wasn't created as a pre-post measure (Buss et al., 2008). Holden and colleagues (2018) modified the MRI-SF to measure MRB twice: within the past year and the next year. However, this may have served as a limitation in this research, as participants may have struggled to predict their future behaviors (Holden et al., 2018). The current study modified the MRI-SF to examine $\mathrm{MRB}$ in the current moment (i.e. state $\mathrm{MRB}$ ) before and after the future alone paradigm. Therefore, the modified MRI-SF may not have accurately captured any changes in MRB if they existed. Thus, future research should examine the validity of the modified MRI-SF using in this study, adapt the MRI-SF into a valid pre-post measure, or invest in another pre-post measure of mate retention.

Finally, limitations could be found within our sample. Firstly, the average age of participants was approximately 37 years old, and many of the participants $(n=187)$ were currently in a relationship. Additionally, BPD typically stabilizes once individuals reach their 30s 
and 40s (APA, 2013). During this time, people with BPD are often able to form and maintain long-term relationships (APA, 2013). In turn, participants may have been further suspicious if they received the negative feedback, where they were told their personality was not compatible with long-term relationships because they were most likely currently in a successful relationship. However, no manipulation check was included to account for this. This emphasizes the importance for future research to include a manipulation check to assess how credible participants perceive the feedback. Secondly, participants were not required to be in a relationship, nor did they interact with their partner while completing the study. Mate retention behaviors occur within the context of relationships. Furthermore, people are highly influenced by the behaviors of their partner. Therefore, our study may have been limited by failing to examine the relationship between BPF, RCSE, and MRB in a dyadic context. Thirdly, our study examined BPD dimensionally (i.e., BPF) among a nonclinical sample. The distribution of BPF across the sample was positively skewed, and only 3 participants were considered to have elevated pathological traits associated with BPD, suggesting that they could potentially be diagnosed with BPD (Calvo et al., 2016). Thus, it is possible that were we limited in our analyses due to the lack of variability in levels of BPF. Using a clinical sample would allow us greater prevalence of BPD features and diagnosis. Future research should continue to examine the relationship between fragile self-esteem, borderline personality disorder, and mate retention through romantic couples and clinical populations, which may provide further insight into how mate retention behaviors impact relationship functioning for those with BPD.

\section{Conclusions}

This research was the first to examine the relationship between borderline personality features and relationship-contingent self-esteem. The purpose of this study was investigate what 
behaviors, maladaptive or not, individuals with high levels of BPF are willing to engage in to prevent infidelity or relationship dissolution and why they are motivated to do so. While our interaction model was not significant, this research still provided insight into the individual differences and how they predict relationship behaviors. Specifically, this study shows that individuals with BPD are likely to engage in negative relationship behaviors, which may potentially and partially explain why their relationships tend to be are unstable and unsatisfying in nature (APA, 2013). In contrast, those with high levels of RCSE primarily engage in positive relationship behaviors. Therefore, while those with BPD and those with RCSE are similar in that they prioritize relationships and exhibit heightened negative affect and distress from relationship dissolution, they may use different means to maintain their relationships. Thus, this study expanded the current literature and our knowledge of interpersonal functioning for individuals with borderline personality disorder. 


\section{References}

American Psychiatric Association. (2013). Diagnostic and statistical manual of mental disorders: DSM-5 (5 ${ }^{\text {th }}$ ed.). Washington, DC: American Psychiatric Publishing.

Atari, M., Barbaro, N., Sela, Y., Shackelford, T. K., \& Chegeni, R. (2017). The Big Five personality dimensions and mate retention behaviors in Iran. Personality and Individual Differences, 104, 286-290. doi:10.1016/j.paid.2016.08.029

Baumeister, R. F., DeWall, C. N., Ciarocco, N. J., \& Twenge, J. M. (2005). Social exclusion impairs self-regulation. Journal of personality and social psychology, 88, 589. doi: $10.1037 / 0022-3514.88 .4 .589$

Baumeister, R. F., \& Leary, M. R. (1995). The need to belong: Desire for interpersonal attachments as a fundamental human motivation. Psychological Bulletin, 117, 497-529. doi:10.1037/0033-2909.117.3.497

Beard, C. L., \& Wickham, R. E. (2016). Gaming-contingent self-worth, gaming motivation, and Internet Gaming Disorder. Computers in Human Behavior, 61, 507-515. doi:10.1016/j.chb.2016.03.046

Berman, W. H. (1988). The role of attachment in the post-divorce experience. Journal of Personality and Social Psychology, 54, 496-503. doi:002205IJ/88/J00.75

Betzig, L. (1989). Causes of conjugal dissolution: A cross-cultural study. Current Anthropology, 30, 654-676. doi:10.1086/203798

Blascovich, J., \& Tomaka, J. (1991). Measures of self-esteem. Measures of personality and social psychological attitudes, 1, 115-160. doi:10.1016/B978-0-12-590241-0.50008-3

Bouchard, S., Sabourin, S., Lussier, Y., \& Villeneuve, E. (2009). Relationship quality and stability in couples when one partner suffers from borderline personality disorder. 
Journal of Marital and Family Therapy, 35, 446-455. doi:10.1111/j.1752-

0606.2009.00151.x

Buss, D. M. (1988). From vigilance to violence: Tactics of mate retention in American undergraduates. Ethology \& Sociobiology, 9, 291-317. doi:10.1016/0162-3095(88)900106

Buss, D. M., \& Shackelford, T. K. (1997). From vigilance to violence: Mate retention tactics in married couples. Journal of Personality and Social Psychology, 72, 346-36. doi: 0O223514/97/S3.O0

Buss, D. M., Shackelford, T. K., \& McKibbin, W. F. (2008). The mate retention inventory-short form (MRI-SF). Personality and Individual Differences, 44, 322-334. doi: 10.1016/j.paid.2007.08.013

Calvo, N., Valero, S., Sáez-Francàs, N., Gutiérrez, F., Casas, M., \& Ferrer, M. (2016). Borderline personality disorder and personality inventory for DSM-5 (PID-5): Dimensional personality assessment with DSM-5. Comprehensive Psychiatry, 70, 105111. doi:10.1016/j.comppsych.2016.07.002

Cambron, M. J., Acitelli, L. K., \& Steinberg, L. (2010). When friends make you blue: The role of friendship contingent self-esteem in predicting self-esteem and depressive symptoms. Personality and Social Psychology Bulletin, 36, 384-397. doi: $10.1177 / 0146167209351593$

Centifanti, L. M., Thomson, N. D., \& Kwok, A. H. (2016). Identifying the manipulative mating methods associated with psychopathic traits and BPD features. Journal of Personality Disorders, 30, 721-741.doi:10.1521/pedi_2015_29_225

Chandler, J., Mueller, P., \& Paolacci, G. (2014). Nonnaïveté among Amazon Mechanical Turk 
workers: Consequences and solutions for behavioral researchers. Behavior research methods, 46, 112-130. doi: 10.3758/s13428-013-0365-7

Clarkin, J. F., Hull, J. W., Cantor, J., \& Sanderson, C. (1993). Borderline personality disorder and personality traits: A comparison of SCID-II BPD and NEO-PI. Psychological Assessment, 5, 472-476. doi:10.1037/1040-3590.5.4.472

Crocker, J., \& Park, L.E. (2004). The costly pursuit of self-esteem. Psychological Bulletin, 130, 392-414. doi:10.1037/0033-2909.130.3.392

Crocker, J., \& Wolfe, C. T. (2001). Contingencies of self-worth. Psychological Review, 108, 593-623. doi:10.1037/0033-295X.108.3.593

Crocker, J., Karpinski, A., Quinn, D.M., \& Chase, S. (2003). When grades determine self-worth: Consequences of contingent self- worth for male and female engineering and psychology majors. Journal of Personality and Social Psychology, 85, 507-516. doi: 10.1037/00223514.85.3.507

Daley, S. E., Burge, D., \& Hammen, C. (2000). Borderline personality disorder symptoms as predictors of 4-year romantic relationship dysfunction in young women: Addressing issues of specificity. Journal of Abnormal Psychology, 109, 451-460. doi:10.1037/0021843X.109.3.451

Davis, A. C., Desrochers, J., DiFilippo, A., Vaillancourt, T., \& Arnocky, S. (2018). Type of jealousy differentially predicts cost-inflicting and benefit-provisioning mate retention. Personal Relationships, 25, 596-610. doi:10.1111/pere.12262

de Miguel, A., \& Buss, D. M. (2011). Mate retention tactics in Spain: Personality, sex differences, and relationship status. Journal of Personality, 79, 563-586. doi: 10.1111/j.1467-6494.2011.00698.x 
DiBello, A. M., Rodriguez, L. M., Hadden, B. W., \& Neighbors, C. (2015). The green-eyed monster in the bottle: Relationship-contingent self-esteem, romantic jealousy, and alcohol-related problems. Addictive Behaviors, 49, 52-58. doi:10.1016/j.addbeh.2015.05.008

Faul, F., Erdfelder, E., Buchner, A., \& Lang, A.-G. (2009). Statistical power analyses using G*Power 3.1: Tests for correlation and regression analyses. Behavior Research Methods, 41, 1149-1160. doi:10.3758/BRM.41.4.1149

Fowler, J. C., Madan, A., Allen, J. G., Patriquin, M., Sharp, C., Oldham, J. M., \& Frueh, B. C. (2018). Clinical utility of the DSM-5 alternative model for borderline personality disorder: Differential diagnostic accuracy of the BFI, SCID-II-PQ, and PID-

5. Comprehensive Psychiatry, 80, 97-103. doi:10.1016/j.comppsych.2017.09.003

Gerber, J., \& Wheeler, L. (2009). On being rejected: A meta-analysis of experimental research on rejection. Perspectives on Psychological Science, 4, 468-488. doi:10.1111/j.17456924.2009.01158.x

Hill, J., Stepp, S. D., Wan, M. W., Hope, H., Morse, J. Q., Steele, M., ... Pilkonis, P. A. (2011). Attachment, borderline personality, and romantic relationship dysfunction. Journal of Personality Disorders, 25, 789-805. doi:10.1521/pedi.2011.25.6.789

Holden, C. J., Roof, C. H., McCabe, G., \& Zeigler-Hill, V. (2015). Detached and antagonistic: Pathological personality features and mate retention behaviors. Personality and Individual Differences, 83, 77-84. doi:10.1016/j.paid.2015.03.054

Holden, C. J., Zeigler, H. V., Shackelford, T. K., \& Welling, L. L. M. (2018). The impact of relationship-contingent self-esteem on mate retention and reactions to threat. Personal Relationships, 25, 611-630. doi:10.1111/pere.12255 
Kaighobadi, F., Shackelford, T. K., \& Buss, D. M. (2010). Spousal mate retention in the newlywed year and three years later. Personality and Individual Differences, 48, 414418. doi:10.1016/j.paid.2009.11.008

Kernis, M. H. (2003). Toward a conceptualization of optimal self-esteem. Psychological Inquiry, 14, 1-26. doi:10.1207/S15327965PLI1401_01

Krueger, R. F., Derringer, J., Markon, K. E., Watson, D., \& Skodol, A. E. (2012). Initial construction of a maladaptive personality trait model and inventory for DSM-5. Psychological Medicine, 42, 1879-1890. doi:10.1017/S0033291711002674

Knee, C. R., Canevello, A., Bush, A. L., \& Cook, A. (2008). Relationship-contingent self-esteem and the ups and downs of romantic relationships. Journal of Personality and Social Psychology, 95, 608-627. doi:10.1037/0022-3514.95.3.608

Lazarus, S. A., Scott, L. N., Beeney, J. E., Wright, A. G. C., Stepp, S. D., \& Pilkonis, P. A. (2018). Borderline personality disorder symptoms and affective responding to perceptions of rejection and acceptance from romantic versus nonromantic partners. Personality Disorders: Theory, Research, and Treatment, 9, 197-206. doi:10.1037/per0000289.supp

Mageau, G. A., Carpentier, J., \& Vallerand, R. J. (2011). The role of self-esteem contingencies in the distinction between obsessive and harmonious passion. European Journal of Social Psychology, 41, 720-729. doi:10.1002/ejsp.798

McKibbin, W. F., Miner, E. J., Shackelford, T. K., Ehrke, A. D., \& Weekes-Shackelford, V. A. (2014). Men's mate retention varies with men's personality and their partner's personality. Personality and Individual Differences, 56, 62-67. doi:10.1016/j.paid.2013.08.022 
Milardo, R. M., Johnson, M. P., \& Huston, T. L. (1983). Developing close relationships: Changing patterns of interaction between pair members and social networks. Journal of Personality and Social Psychology, 44, 964-976. doi:10.1037/0022-3514.44.5.964

Miller, J. D., Crowe, M., Weiss, B., Maples-Keller, J. L., \& Lynam, D. R. (2017). Using online, crowdsourcing platforms for data collection in personality disorder research: The example of Amazon's Mechanical Turk. Personality Disorders: Theory, Research, and Treatment, 8, 26-34. doi:10.1037/per0000191

Miner, E. J., Starratt, V. G., \& Shackelford, T. K. (2009). It's not all about her: Men's mate value and mate retention. Personality and Individual Differences, 47, 214-218. doi:10.1016/j.paid.2009.03.002

Murray, S. L. (2005). Regulating the risks of closeness: A relationship-specific sense of felt security. Current Directions in Psychological Science, 14, 74-78. doi:10.1111/j.09637214.2005.00338.x

Murray, S. L., Griffin, D. W., Rose, P., \& Bellavia, G. (2006). For better or worse? Self-esteem and the contingencies of acceptance in marriage. Personality and Social Psychology Bulletin, 32, 866-880. doi:10.1177/0146167206286756

Murray, S. L., Holmes, J. G., \& Griffin, D. (1996). The benefits of positive illusions: Idealization and the construction of satisfaction in close relationships. Journal of Personality and Social Psychology, 70, 79-98. doi:10.1037/0022-3514.70.1.79

Murray, S. L., Holmes, J. G., \& Griffin, D. W. (2000). Self-esteem and the quest for felt security: How perceived regard regulates attachment processes. Journal of Personality and Social Psychology, 78, 478-498. doi:10.1037/0022-3514.78.3.478

Murray, S. L., Holmes, J. G., MacDonald, G., \& Ellsworth, P. C. (1998). Through the looking 
glass darkly? When self-doubts turn into relationship insecurities. Journal of Personality and Social Psychology, 75, 1459-1480. doi:10.1037/0022-3514.75.6.1459

Murray, S. L., Leder, S., MacGregor, J. C. D., Holmes, J. G., Pinkus, R. T., \& Harris, B. (2009). Becoming irreplaceable: How comparisons to the partner's alternatives differentially affect low and high self-esteem people. Journal of Experimental Social Psychology, 45, 1180-1191. doi:10.1016/j.jesp.2009.07.001

Murray, S. L., Rose, P., Bellavia, G. M., Holmes, J. G., \& Kusche, A. G. (2002). When rejection stings: How self-esteem constrains relationship-enhancement processes. Journal of Personality and Social Psychology, 83, 556-573. doi: https://doi.org/10.1037//00223514.83.3.556

Park, L. E., Sanchez, D. T., \& Brynildsen, K. (2011). Maladaptive responses to relationship dissolution: The role of relationship contingent self-worth. Journal of Applied Social Psychology, 41, 1749-1773. doi:10.1111/j.1559-1816.2011.00769.x

Rodriguez, L. M., Knee, C. R., \& Neighbors, C. (2014). Relationships can drive some to drink: Relationship-contingent self-esteem and drinking problems. Journal of Social and Personal Relationships, 31, 270-290. doi:10.1177/0265407513494037

Rosenberg, M. (1965). Society and the adolescent self-image. Princeton, NJ: Princeton University Press.

Rosenthal, M. Z., Gratz, K. L., Kosson, D. S., Cheavens, J. S., Lejuez, C. W., \& Lynch, T. R. (2008). Borderline personality disorder and emotional responding: A review of the research literature. Clinical Psychology Review, 28, 75-91. doi:10.1016/j.cpr.2007.04.001

Salkicevic, S., Stanic, A. L., Grabovac, M. T. (2014). Good mates retain us right: Investigating 
the relationship between mate retention strategies, mate value, and relationship satisfaction. Evolutionary Psychology, 12, 1038-1052.

doi:10.1177/147470491401200512

Sanchez, D. T., Good, J. J., Kwang, T., \& Saltzman, E. (2008). When finding a mate feels urgent: Why relationship contingency predicts men's and women's body shame. Social Psychology, 39, 90-102. doi:10.1027/1864-9335.39.2.90

Sanchez, D. T., \& Kwang, T. (2007). When the relationship becomes her: Revisiting women's body concerns from a relationship contingency perspective. Psychology of Women Quarterly, 31, 401-414. doi:10.1111/j.1471-6402.2007.00389.x

Sanchez, D. T., Moss-Racusin, C. A., Phelan, J. E., \& Crocker, J. (2011). Relationship contingency and sexual motivation in women: Implications for sexual satisfaction. Archives of Sexual Behavior, 40, 99-110. doi:10.1007/s10508-009-9593-4

Selby, E. A., Braithwaite, S. R., Joiner, T. E., Jr., \& Fincham, F. D. (2008). Features of borderline personality disorder, perceived childhood emotional invalidation, and dysfunction within current romantic relationships. Journal of Family Psychology, 22, 885-893. doi:10.1037/a0013673

Shackelford, T. K., \& Buss, D. M. (2000). Marital satisfaction and spousal costinfliction. Personality and Individual Differences, 28, 917-928. doi:10.1016/S01918869(99)00150-6

Shackelford, T. K., Goetz, A. T., \& Buss, D. M. (2005). Mate retention in marriage: Further evidence of the reliability of the Mate Retention Inventory. Personality and Individual Differences, 39, 415-425. doi:10.1016/j.paid.2005.01.018

Tragesser, S. L., \& Benfield, J. (2012). Borderline personality disorder features and mate 
retention tactics. Journal of Personality Disorders, 26, 334-344.

doi:10.1521/pedi.2012.26.3.334

Twenge, J. M., Baumeister, R. F., Tice, D. M., \& Stucke, T. S. (2001). If you can't join them, beat them: Effects of social exclusion on aggressive behavior. Journal of Personality and Social Psychology, 81, 1058-1069. doi:10.1037//0022-3514.81.6.1058

Widiger, T. A. (2011). The DSM-5 dimensional model of personality disorder: Rationale and empirical support. Journal of Personality Disorders, 25, 222-234.

doi:10.1521/pedi.2011.25.2.222

Widiger, T. A. \& Trull, T. J. (2011). Plate tectonics in the classification of personality disorder: Shifting to a dimensional model. American Psychologist, 62, 71-83. doi:10.1037/0003 066X.62.2.71

Willis, M., \& Nelson-Gray, R. O. (2017). Borderline personality disorder traits and sexual compliance: A fear of abandonment manipulation. Personality and Individual Differences, 117, 216-220. doi:10.1016/j.paid.2017.06.012

Zeigler-Hill, V. (2013). Self-esteem. (V. Zeigler-Hill, Ed.). New York, NY: Psychology Press.

Zeigler-Hill, V., \& Abraham, J. (2006). Borderline personality features: Instability of self-esteem and affect. Journal of Social and Clinical Psychology, 25, 668-687. doi:10.1521/jscp.2006.25.6.668 
Tables and Figures

Table 1

Correlations between Main Predictor Variables and Outcome Variables.

\begin{tabular}{|c|c|c|c|c|c|c|c|}
\hline Variable & 1 & 2 & 3 & 4 & 5 & 6 & 7 \\
\hline 1. $\mathrm{BPF}$ & - & & & & & & \\
\hline 2. RCSE & .08 & - & & & & & \\
\hline 3. Self-Esteem & $-.52 * * *$ & $-.18 * *$ & - & & & & \\
\hline 4. Pre-CI-MRB & $.62 * * *$ & .12 & $-.21 * *$ & - & & & \\
\hline 5. Pre-BP-MRB & .14 & $.49 * * *$ & .06 & $.48 * * *$ & - & & \\
\hline 6. Post-CI-MRB & $.61 * * *$ & .13 & $-.20 * *$ & $.95 * * *$ & $.48 * * *$ & - & \\
\hline 7. Post-BP-MRB & .14 & $.47 * * *$ & .06 & $.45 * * *$ & $.91 * * *$ & $.49 * * *$ & - \\
\hline Mean & 0.82 & 3.60 & 3.73 & 1.56 & 2.47 & 1.53 & 2.44 \\
\hline SD & 0.46 & 0.83 & 0.98 & 0.53 & 0.66 & 0.54 & 0.72 \\
\hline
\end{tabular}

Note. Pre-CI-MRB stands for pre-measures of cost-inflicting mate retention behaviors. Pre-BP$\mathrm{MRB}$ represents the pre-measures of benefit-provisioning mate retention behaviors. Post-CI$\mathrm{MRB}$ and Post-BP-MRB stand for post-measures of cost-inflicting and benefit-provisioning mate retention behaviors.

$* * * p<.001 . * * p<.01 . * p<.05$. 
Table 2

Three-Way Interaction Regression Model.

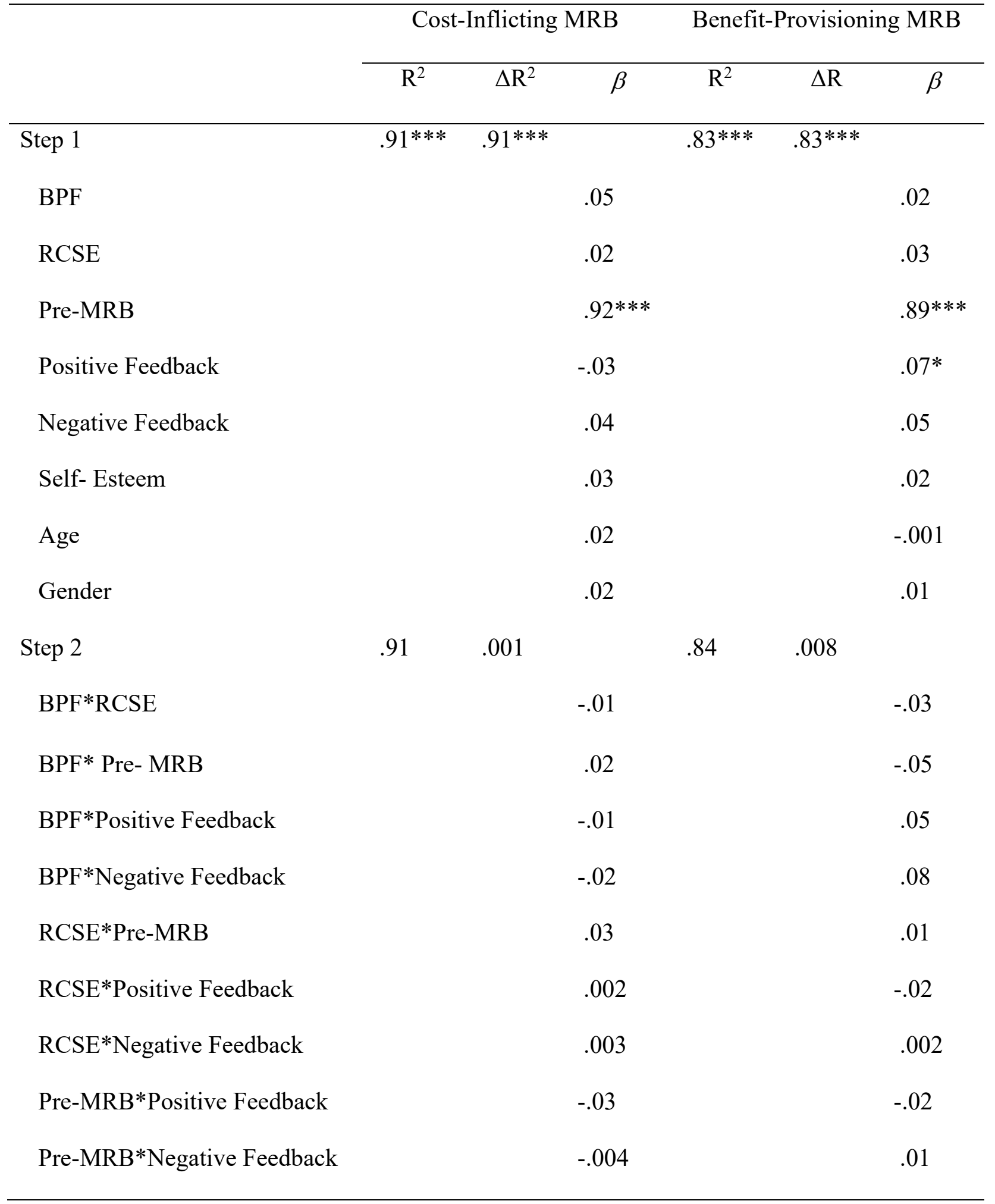




\begin{tabular}{|c|c|c|c|c|c|c|}
\hline & \multicolumn{3}{|c|}{ Cost-Inflicting MRB } & \multicolumn{3}{|c|}{ Benefit-Provisioning MRB } \\
\hline & $\mathrm{R}^{2}$ & $\Delta \mathrm{R}$ & $\beta$ & $\mathrm{R}^{2}$ & $\Delta \mathrm{R}$ & $\beta$ \\
\hline Step 3 & .92 & .005 & & .85 & .005 & \\
\hline BPF*RCSE*Pre-MRB & & & .06 & & & .02 \\
\hline $\begin{array}{l}\text { BPF*RCSE*Positive } \\
\text { Feedback }\end{array}$ & & & .01 & & & .01 \\
\hline $\begin{array}{l}\text { BPF*RCSE* Negative } \\
\text { Feedback }\end{array}$ & & & -.05 & & & .01 \\
\hline $\begin{array}{l}\text { RCSE*Pre-MRB*Positive } \\
\text { Feedback }\end{array}$ & & & -.03 & & & -.05 \\
\hline $\begin{array}{l}\text { RCSE*Pre-MRB*Negative } \\
\text { Feedback }\end{array}$ & & & -.03 & & & .01 \\
\hline $\begin{array}{l}\text { Pre-MRB*BPF*Positive } \\
\text { Feedback }\end{array}$ & & & .03 & & & .05 \\
\hline $\begin{array}{l}\text { Pre-MRB*BPF* Negative } \\
\text { Feedback }\end{array}$ & & & -.01 & & & -.05 \\
\hline
\end{tabular}

Note. Some variables were excluded because they did not account for any of the variance within the model.

$* * * p<.001 . * * p<.01 . * p<.05$. 
Table 3

Correlations between Variables of Interest and Control Variables.

\begin{tabular}{|c|c|c|c|c|c|c|c|c|c|}
\hline Variable & 1 & 2 & 3 & 4 & 5 & 6 & 7 & 8 & 9 \\
\hline 1. $\mathrm{BPF}$ & - & & & & & & & & \\
\hline 2. RCSE & .08 & - & & & & & & & \\
\hline 3. Self-Esteem & $-.50 * * *$ & $-.18 * *$ & - & & & & & & \\
\hline 4. Post-CI-MRB & $.61 * * *$ & .13 & $-.20 * *$ & - & & & & & \\
\hline 5. Post-BP-MRB & .14 & $.47 * * *$ & .06 & $.49 * * *$ & - & & & & \\
\hline 6. Age & $-.18 * *$ & $-.21 * *$ & $.23 * *$ & -.11 & -.10 & - & & & \\
\hline $\begin{array}{l}\text { 7. Relationship } \\
\text { Length }\end{array}$ & $-.20 * *$ & -.08 & $.21 * *$ & -.08 & -.07 & $.45 * * *$ & - & & \\
\hline 8. Relationship Status & -.08 & $-.20 * *$ & .08 & .11 & $.23 * *$ & -.05 & $.30 * * *$ & - & \\
\hline 9. Gender & -.09 & -.11 & -.09 & -.04 & -.10 & $.17 *$ & $.27 * * *$ & .12 & \\
\hline Mean & 0.82 & 3.60 & 3.73 & 1.53 & 2.44 & 36.76 & 90.61 & 2.79 & - \\
\hline SD & 0.46 & 0.83 & 0.98 & 0.54 & 0.72 & 10.64 & 96.84 & 0.60 & - \\
\hline
\end{tabular}

Note. Gender was coded as 0 for males and 1 for females. For relationship status, $1=$ single, $2=$ unsure, and $3=$ in a relationship. $* * * p<.001 . * * p<.01 . * p<.05$. 
Table 4

Regressions for BPF and RCSE on Benefit-provisioning MRB and Cost-Inflicting MRB

\begin{tabular}{|c|c|c|c|c|c|c|}
\hline & \multicolumn{3}{|c|}{ Cost-Inflicting MRB } & \multicolumn{3}{|c|}{ Benefit-Provisioning MRB } \\
\hline & $\mathrm{R}^{2}$ & $\Delta \mathrm{R}$ & $\beta$ & $\mathrm{R}^{2}$ & $\Delta \mathrm{R}$ & $\beta$ \\
\hline Step 1 & $.38 * * *$ & $.38 * * *$ & & $.23 * * *$ & $.23 * * *$ & \\
\hline $\mathrm{BPF}$ & & & $.60 * * *$ & & & .10 \\
\hline RCSE & & & .08 & & & $.46^{* * *}$ \\
\hline
\end{tabular}


Table 5

Correlations between BPF, RCSE, and Benefit-provisioning Mate Retention Tactics.

\begin{tabular}{|c|c|c|c|c|c|c|c|c|c|c|}
\hline Variable & 1 & 2 & 3 & 4 & 5 & 6 & 7 & 8 & 9 & 10 \\
\hline 1. $\mathrm{BPF}$ & & & & & & & & & & \\
\hline 2. RCSE & .08 & - & & & & & & & & \\
\hline 3. Resource Display & -.01 & $.26 * * *$ & - & & & & & & & \\
\hline 4. Sexual Inducements & $.17^{*}$ & $.33 * * *$ & $.58 * * *$ & - & & & & & & \\
\hline 5. Appearance Enhancement & .07 & $.34 * * *$ & $.63 * * *$ & $.59 * * *$ & - & & & & & \\
\hline 6. Love and Care & -.08 & $.43 * * *$ & $.66^{* * *}$ & $.58 * * *$ & $.66^{* * *}$ & - & & & & \\
\hline $\begin{array}{l}\text { 7. Submission and } \\
\text { Debasement }\end{array}$ & $.29 * * *$ & $.32 * * *$ & $.27 * * *$ & $.51 * * *$ & $.28 * * *$ & $.21 * *$ & - & & & \\
\hline 8. Verbal Possession Signals & .12 & $.46^{* * *}$ & $.55 * * *$ & $.49 * * *$ & $.51 * * *$ & $.55 * * *$ & $.47 * * *$ & - & & \\
\hline 9. Physical Possession Signals & .04 & $.41 * * *$ & $.54 * * *$ & $.54 * * *$ & $.49 * * *$ & $.64 * * *$ & $.27 * * *$ & $.65 * * *$ & - & \\
\hline 10. Possessive Ornamentation & $.18^{* *}$ & $.27 * * *$ & $.60 * * *$ & $.52 * * *$ & $.45 * * *$ & $.37 * * *$ & $.49 * * *$ & $.62 * * *$ & $.52 * * *$ & - \\
\hline Mean & 0.82 & 3.60 & 2.72 & 2.52 & 2.65 & 3.07 & 1.72 & 2.21 & 2.79 & 2.04 \\
\hline SD & 0.46 & 0.83 & 0.89 & 0.84 & 0.90 & 0.91 & 0.82 & 0.99 & 1.02 & 0.99 \\
\hline
\end{tabular}


Table 6

Correlations between BPF, RCSE, and Cost-inflicting Mate Retention Tactics.

\begin{tabular}{|c|c|c|c|c|c|c|c|c|c|c|c|c|c|}
\hline Variable & 1 & 2 & 3 & 4 & 5 & 6 & 7 & 8 & 9 & 10 & 11 & 12 & 13 \\
\hline 1. $\mathrm{BPF}$ & - & & & & & & & & & & & & \\
\hline 2. RCSE & .08 & - & & & & & & & & & & & \\
\hline 3. Vigilance & $.50 * * *$ & .02 & - & & & & & & & & & & \\
\hline $\begin{array}{l}\text { 4. Concealment of } \\
\text { mate }\end{array}$ & $.46 * * *$ & -.01 & $.62 * * *$ & - & & & & & & & & & \\
\hline $\begin{array}{l}\text { 5. Monopolization } \\
\text { of time }\end{array}$ & $.49 * * *$ & $.15^{*}$ & $.68 * * *$ & $.61 * * *$ & - & & & & & & & & \\
\hline $\begin{array}{l}\text { 6. Jealously } \\
\text { Induction }\end{array}$ & $.60 * * *$ & -.05 & $.62 * * *$ & $.58 * * *$ & $.58 * * *$ & - & & & & & & & \\
\hline $\begin{array}{l}\text { 7. Punish Mate's } \\
\text { Infidelity } \\
\text { Threat }\end{array}$ & $.34 * * *$ & .13 & $.45 * * *$ & $.43 * * *$ & $.35 * * *$ & $.32 * * *$ & - & & & & & & \\
\hline $\begin{array}{l}\text { 8. Emotional } \\
\text { Manipulation }\end{array}$ & $.43 * * *$ & $.28 * * *$ & $.48 * * *$ & $.43 * * *$ & $.63 * * *$ & $.38 * * *$ & $.45 * * *$ & - & & & & & \\
\hline $\begin{array}{l}\text { 9. Commitment } \\
\text { Manipulation }\end{array}$ & .12 & $.35 * * *$ & $.35 * * *$ & $.27 * * *$ & $.40 * * *$ & $.16^{*}$ & $.39 * * *$ & $.52 * * *$ & - & & & & \\
\hline $\begin{array}{l}\text { 10. Derogation of } \\
\text { Competitors }\end{array}$ & $.47 * * *$ & .11 & $.55 * * *$ & $.51 * * *$ & $.46 * * *$ & $.46^{* * *}$ & $.53 * * *$ & $.52 * * *$ & $.31 * * *$ & - & & & \\
\hline $\begin{array}{l}\text { 11. Derogation of } \\
\text { Mate }\end{array}$ & $.51 * * *$ & .001 & $.59 * * *$ & $.47 * * *$ & $.60 * * *$ & $.54 * * *$ & $.28 * *$ & $.43 * * *$ & .12 & $.44 * * *$ & - & & \\
\hline $\begin{array}{l}\text { 12. Intrasexual } \\
\text { Threats }\end{array}$ & $.45 * * *$ & .08 & $.47 * * *$ & $.54 * * *$ & $.47 * * *$ & $.46 * * *$ & $.57 * * *$ & $.42 * * *$ & $.24 * *$ & $.61 * * *$ & $.41 * * *$ & - & \\
\hline $\begin{array}{l}\text { 13. Violence } \\
\text { Against Rivals }\end{array}$ & $.54 * * *$ & -.03 & $.61 * * *$ & $.48 * * *$ & $.59 * * *$ & $.57 * * *$ & $.38 * * *$ & $.49 * * *$ & $.24 * * *$ & $.51 * * *$ & $.58 * * *$ & $.58 * * *$ & - \\
\hline
\end{tabular}




\begin{tabular}{cccccccccccccc}
\hline Mean & 0.82 & 3.60 & 1.54 & 1.46 & 1.45 & 1.28 & 1.99 & 1.50 & 2.21 & 1.65 & 1.36 & 1.60 & 1.23 \\
SD & 0.46 & 0.83 & 0.78 & 0.74 & 0.77 & 0.66 & 0.96 & 0.75 & 0.96 & 0.83 & 0.64 & 0.88 & 0.53 \\
& & & & & & & & & & & & &
\end{tabular}


Appendices

Appendix A

\section{Demographic Questionnaire}

1. What is the current status of your romantic relationship?
a. In a relationship
b. Single
c. Unsure

2. How long have you been in your current romantic relationship?
a. Number of Years: [Text box]
b. Number of Months: [Text box]

3. What is your age (in years)?
a. [Text box]

4. What is your gender?
a. Male
b. Female
c. Nonbinary
d. Other

5. What is your race/ethnicity?
a. White
b. Black of African American
c. American Indian or Alaska Native
d. Asian
e. Native Hawaiian or Pacific Islander 

f. Hispanic or Latino
g. Other

6. What is your sexual orientation?
a. Heterosexual
b. Homosexual
c. Bisexual or Pansexual
d. Asexual
e. Other 


\section{Appendix B \\ Personality Inventory for the DSM-5 (Kruger et al., 2012)}

Instructions: This is a list of things different people might say about themselves. We are interested in how you would describe yourself. There are no "right" or "wrong" answers. So, you can describe yourself as honestly as possible, we will keep your responses confidential. We'd like you to take your time and read each statement carefully, selecting the response that best describes you.

$\begin{array}{crrr}\text { Very False or Often } & \text { Sometimes or } & \text { Sometimes or } & \text { Very True or Often } \\ \text { False (0) } & \text { Somewhat False (1) } & \text { Somewhat True (2) } & \text { True (3) }\end{array}$

1. I don't get as much pleasure out of things as others seem to.

2. Plenty of people are out to get me.

3. People would describe me as reckless.

4. I feel like I act totally on impulse.

5. I often have ideas that are too unusual to explain to anyone.

6. I lose track of conversations because other things catch my attention.

7. I avoid risky situations.

8. When it comes to my emotions, people tell me I'm a "cold fish".

9. I change what I do depending on what others want.

10. I prefer not to get too close to people.

11. I often get into physical fights.

12. I dread being without someone to love me.

13. Being rude and unfriendly is just a part of who I am. 
14. I do things to make sure people notice me.

15. I usually do what others think I should do.

16. I usually do things on impulse without thinking about what might happen as a result.

17. Even though I know better, I can't stop making rash decisions.

18. My emotions sometimes change for no good reason.

19. I really don't care if I make other people suffer.

20. I keep to myself.

21. I often say things that others find odd or strange.

22. I always do things on the spur of the moment.

23. Nothing seems to interest me very much.

24. Other people seem to think my behavior is weird.

25. People have told me that I think about things in a really strange way.

26. I almost never enjoy life.

27. I often feel like nothing I do really matters.

28. I snap at people when they do little things that irritate me.

29. I can't concentrate on anything.

30. I'm an energetic person.

31. Others see me as irresponsible.

32. I can be mean when I need to be.

33. My thoughts often go off in odd or unusual directions.

34. I've been told that I spend too much time making sure things are exactly in place.

35. I avoid risky sports and activities.

36. I can have trouble telling the difference between dreams and waking life. 
37. Sometimes I get this weird feeling that parts of my body feel like they're dead or not really me.

38. I am easily angered.

39. I have no limits when it comes to doing dangerous things.

40. To be honest, I'm just more important than other people.

41. I make up stories about things that happened that are totally untrue.

42. People often talk about me doing things I don't remember at all.

43. I do things so that people just have to admire me.

44. It's weird, but sometimes ordinary objects seem to be a different shape than usual.

45. I don't have very long-lasting emotional reactions to things.

46. It is hard for me to stop an activity, even when it's time to do so.

47. I'm not good at planning ahead.

48. I do a lot of things that others consider risky.

49. People tell me that I focus too much on minor details.

50. I worry a lot about being alone.

51. I've missed out on things because I was busy trying to get something I was doing exactly right.

52. My thoughts often don't make sense to others.

53. I often make up things about myself to help me get what I want.

54. It doesn't really bother me to see other people get hurt.

55. People often look at me as if I'd said something really weird.

56. People don't realize that I'm flattering them to get something.

57. I'd rather be in a bad relationship than be alone. 
58. I usually think before I act.

59. I often see vivid dream-like images when I'm falling asleep or waking up.

60. I keep approaching things the same way, even when it isn't working.

61. I'm very dissatisfied with myself.

62. I have much stronger emotional reactions than almost everyone else.

63. I do what other people tell me to do.

64. I can't stand being left alone, even for a few hours.

65. I have outstanding qualities that few others possess.

66. The future looks really hopeless to me.

67. I like to take risks.

68. I can't achieve goals because other things capture my attention.

69. When I want to do something, I don't let the possibility that it might be risky stop me.

70. Others seem to think I'm quite odd or unusual.

71. My thoughts are strange and unpredictable.

72. I don't care about other people's feelings.

73. You need to step on some toes to get what you want in life.

74. I love getting the attention of other people.

75. I go out of my way to avoid any kind of group activity.

76. I can be sneaky if it means getting what I want.

77. Sometimes when I look at a familiar object, it's somehow like I'm seeing it for the first time.

78. It is hard for me to shift from one activity to another.

79. I worry a lot about terrible things that might happen.

80. I have trouble changing how I'm doing something even if what I'm doing isn't going well. 
81. The world would be better off if I were dead.

82. I keep my distance from people.

83. I often can't control what I think about.

84. I don't get emotional.

85. I resent being told what to do, even by people in charge.

86. I'm so ashamed by how I've let people down in lots of little ways.

87. I avoid anything that might be even a little bit dangerous.

88. I have trouble pursuing specific goals even for short periods of time.

89. I prefer to keep romance out of my life.

90. I would never harm another person.

91. I don't show emotions strongly.

92. I have a very short temper.

93. I often worry that something bad will happen due to mistakes I made in the past.

94. I have some unusual abilities, like sometimes knowing exactly what someone is thinking.

95. I get very nervous when I think about the future.

96. I rarely worry about things.

97. I enjoy being in love.

98. I prefer to play it safe rather than take unnecessary chances.

99. I sometimes have heard things that others couldn't hear.

100. I get fixated on certain things and can't stop.

101. People tell me it's difficult to know what I'm feeling.

102. I am a highly emotional person.

103. Others would take advantage of me if they could. 
104. I often feel like a failure.

105. If something I do isn't absolutely perfect, it's simply not acceptable.

106. I often have unusual experiences, such as sensing the presence of someone who isn't actually there.

107. I'm good at making people do what I want them to do.

108. I break off relationships if they start to get close.

109. I'm always worrying about something.

110. I worry about almost everything.

111. I like standing out in a crowd.

112. I don't mind a little risk now and then.

113. My behavior is often bold and grabs peoples' attention.

114. I'm better than almost everyone else.

115. People complain about my need to have everything all arranged.

116. I always make sure I get back at people who wrong me.

117. I'm always on my guard for someone trying to trick or harm me.

118. I have trouble keeping my mind focused on what needs to be done.

119. I talk about suicide a lot.

120. I'm just not very interested in having sexual relationships.

121. I get stuck on things a lot.

122. I get emotional easily, often for very little reason.

123. Even though it drives other people crazy, I insist on absolute perfection in everything I do.

124. I almost never feel happy about my day-to-day activities. 
125. Sweet-talking others helps me get what I want.

126. Sometimes you need to exaggerate to get ahead.

127. I fear being alone in life more than anything else.

128. I get stuck on one way of doing things, even when it's clear it won't work.

129. I'm often pretty careless with my own and others' things.

130. I am a very anxious person.

131. People are basically trustworthy.

132. I am easily distracted.

133. It seems like I'm always getting a "raw deal" from others.

134. I don't hesitate to cheat if it gets me ahead.

135. I check things several times to make sure they are perfect.

136. I don't like spending time with others.

137. I feel compelled to go on with things even when it makes little sense to do so.

138. I never know where my emotions will go from moment to moment.

139. I have seen things that weren't really there.

140. It is important to me that things are done in a certain way.

141. I always expect the worst to happen.

142. I try to tell the truth even when it's hard.

143. I believe that some people can move things with their minds.

144. I can't focus on things for very long.

145. I steer clear of romantic relationships.

146. I'm not interested in making friends.

147. I say as little as possible when dealing with people. 
148. I'm useless as a person.

149. I'll do just about anything to keep someone from abandoning me.

150. Sometimes I can influence other people just by sending my thoughts to them.

151. Life looks pretty bleak to me.

152. I think about things in odd ways that don't make sense to most people.

153. I don't care if my actions hurt others.

154. Sometimes I feel "controlled" by thoughts that belong to someone else.

155. I really live life to the fullest.

156. I make promises that I don't really intend to keep.

157. Nothing seems to make me feel good.

158. I get irritated easily by all sorts of things.

159. I do what I want regardless of how unsafe it might be.

160. I often forget to pay my bills.

161. I don't like to get too close to people.

162. I'm good at conning people.

163. Everything seems pointless to me.

164. I never take risks.

165. I get emotional over every little thing.

166. It's no big deal if I hurt other peoples' feelings.

167. I never show emotions to others.

168. I often feel just miserable.

169. I have no worth as a person.

170. I am usually pretty hostile. 
171. I've skipped town to avoid responsibilities.

172. I've been told more than once that I have a number of odd quirks or habits.

173. I like being a person who gets noticed.

174. I'm always fearful or on edge about bad things that might happen.

175. I never want to be alone.

176. I keep trying to make things perfect, even when I've gotten them as good as they're likely to get.

177. I rarely feel that people I know are trying to take advantage of me.

178. I know I'll commit suicide sooner or later.

179. I've achieved far more than almost anyone I know.

180. I can certainly turn on the charm if I need to get my way.

181. My emotions are unpredictable.

182. I don't deal with people unless I have to.

183. I don't care about other peoples' problems.

184. I don't react much to things that seem to make others emotional.

185. I have several habits that others find eccentric or strange.

186. I avoid social events.

187. I deserve special treatment.

188. It makes me really angry when people insult me in even a minor way.

189. I rarely get enthusiastic about anything.

190. I suspect that even my so-called "friends" betray me a lot.

191. I crave attention.

192. Sometimes I think someone else is removing thoughts from my head. 
193. I have periods in which I feel disconnected from the world or from myself.

194. I often see unusual connections between things that most people miss.

195. I don't think about getting hurt when I'm doing things that might be dangerous.

196. I simply won't put up with things being out of their proper places.

197. I often have to deal with people who are less important than me.

198. I sometimes hit people to remind them who's in charge

199. I get pulled off-task by even minor distractions.

200. I enjoy making people in control look stupid.

201. I just skip appointments or meetings if I'm not in the mood.

202. I try to do what others want me to do.

203. I prefer being alone to having a close romantic partner.

204. I am very impulsive.

205. I often have thoughts that make sense to me but that other people say are strange.

206. I use people to get what I want.

207. I don't see the point in feeling guilty about things I've done that have hurt other people.

208. Most of the time I don't see the point in being friendly.

209. I've had some really weird experiences that are very difficult to explain.

210. I follow through on commitments.

211. I like to draw attention to myself.

212. I feel guilty much of the time.

213. I often "zone out" and then suddenly come to and realize that a lot of time has passed.

214. Lying comes easily to me.

215. I hate to take chances. 
216. I'm nasty and short to anybody who deserves it.

217. Things around me often feel unreal, or more real than usual.

218. I'll stretch the truth if it's to my advantage.

219. It is easy for me to take advantage of others.

220. I have a strict way of doing things. 


\section{Appendix C}

Rosenberg Self-Esteem Scale (Rosenberg, 1965)

Rate the items using the following scale:

\begin{tabular}{|c|c|c|c|c|}
\hline Strongly & Disagree (2) & Neither Agree & Agree (4) & Strongly Agree \\
\hline Disagree (1 & & nor Disagree & & (5) \\
\hline
\end{tabular}

1. I feel that I am a person of worth, at least on an equal basis with others.

2. I feel that I have a number of good qualities.

3. All in all, I am inclined to feel that I am a failure.

4. I am able to do things as well as most other people.

5. I feel I do not have much to be proud of.

6. I take a positive attitude toward myself.

7. On the whole, I am satisfied with myself.

8. I wish I could have more respect for myself.

9. I certainly feel useless at times.

10. At times, I think I am no good at all. 


\section{Appendix D \\ Relationship-Contingent Self-Esteem Scale (Knee et al., 2008)}

Rate the items using the following scale:

Not Like Me (1)

Somewhat Like

Me (3)
Very Much Like

Me (5)

1. I feel better about myself when it seems like my partner and I are getting along.

2. I feel better about myself when it seems like my partner and I are emotionally connected.

3. An important measure of my self-worth is how successful my relationship is.

4. My feelings of self-worth are based on how well things are going in my relationship.

5. When my relationship is going well, I feel better about myself overall.

6. If my relationship were to end tomorrow, I would not let it affect how I feel about myself.

7. My self-worth is unaffected when things go wrong in my relationship.

8. When my partner and I fight, I feel bad about myself in general.

9. When my relationship is going bad, my feelings of self-worth remain unaffected.

10. I feel better about myself when others tell me that my partner and I have a good relationship.

11. When my partner criticizes me, or seems disappointed in me, it makes me feel really bad. 


\section{Appendix E \\ Mate-Retention Inventory-Short Form (Buss et al., 2008)}

Instructions: For each act, use the following scale to indicate how likely you are to perform these acts right now ${ }^{1}$ :

Not at all Likely (1) Somewhat Likely (2) Likely (3) V $\quad$ Very Likely (4)

1. Called to make sure my partner was where they said they would be.

2. Did not take my partner to a party where other people would be present.

3. Insisted that my partner spend all their free time with me.

4. Talked to another person at a party to make my partner jealous.

5. Became angry when my partner flirted too much.

6. Pleaded that I could not live without my partner.

7. Told my partner that we needed a total commitment to each other.

8. Pointed out to my partner the flaws of another person.

9. Bought my partner an expensive gift.

10. Performed sexual favors to keep my partner around.

11. Made myself "extra attractive" for my partner.

12. Complimented my partner on their appearance.

13. Gave in to my partner's every wish.

14. Told my same-sex friends how much my partner and I were in love.

15. Put my arm around my partner in front of others.

\footnotetext{
${ }^{1}$ While the MRI-SF will be administered twice to participants, no changes will be made to either administration.
} 
16. Asked my partner to wear my ring.

17. Told other people that my partner was a pain.

18. Stared coldly at a person who was looking at my partner.

19. Got my friends to beat up someone who was interested in my partner.

20. Snooped through my partner's personal belongings.

21. Took my partner away from a gathering where other people were around.

22. Spent all my free time with my partner so that they could not meet anyone else.

23. Showed interest in another person to make my partner angry.

24. Threatened to break-up if my partner ever cheated on me.

25. Told my partner that I was dependent on my partner.

26. Asked my partner to marry me.

27. Told my partner that another person was stupid.

28. Took my partner out to a nice restaurant.

29. Had a physical relationship with my partner to deepen our bond.

30. Made sure that I looked nice for my partner.

31. Displayed greater affection for my partner.

32. Went along with everything my partner said.

33. Bragged about my partner to other people.

34. Held my partner's hand while other people were around.

35. Gave my partner jewelry to signify that they were taken.

36. Told other people that my partner was not a nice person.

37. Gave a person a dirty look when they looked at my partner.

38. Slapped a person who made a pass at my partner. 


\section{Appendix F}

Modified Future Alone Manipulation (Twenge et al., 2001)

Prompt $^{2}$ : We are currently scoring your responses on the personality measures you just completed. Please be patient as we put together your results. Once they are ready, they will appear on a new screen. Also, please carefully read and consider the feedback once you receive it.

\section{Negative Feedback}

Based on your responses to the previous questions, you're the type of person who will end up alone later in life. You may have friends and relationships now, but later in life most of these will have drifted away. You may even marry or have several marriages, but these are likely to be short-lived. Relationships don't last, and when you're past the age where people are constantly forming new relationships, the odds are you'll end up being alone more and more.

\section{Positive Feedback}

Based on your responses to the previous questions, you're the type who has rewarding relationships throughout life. You're likely to have a long and stable partnership and have friendships that will last into your later years. The odds are that you'll always have friends and people who care about you.

\section{Negative Control (Neutral) Feedback}

Based on your responses to the previous questions, you're likely to be accident prone later in life-you might break an arm or a leg a few times, or may be injured in car accidents. Even if you haven't been accident prone before, these things will show up later in life, and the odds are

\footnotetext{
${ }^{2}$ The prompt will be given to every participant. After 30 seconds has passed, participants will be allowed to continue to a new page where they will be given one of three types of feedback.
} 
you will have a lot of accidents. 


\section{Appendix G}

Consent Form

\section{Information to Consider about this Research \\ Personality and Relationships}

Principal Investigator: Sierra Rufino, B.S.

Co-Investigator: Christopher J. Holden, Ph.D.

Department: Psychology

Contact Information: holdencj@appstate.edu or (828)262-8948

You are invited to participate in a research study investigating the relationship between personality traits, self-esteem, and the types of behaviors people engage in when in a romantic relationship to retain their partner.

If you agree to be part of the research study, you will be asked to complete anonymous demographic information and a questionnaire. The questionnaire includes items that ask you to report judgments about your personality and your use of certain behaviors when in a romantic relationship. Shortly after, you will receive some feedback regarding your personality. In total, this questionnaire should take approximately 25 minutes to complete.

Please be aware that any work performed on Amazon MTurk can potentially be linked to information about you on your Amazon public profile page, depending on the settings you have for your Amazon profile. We will not be accessing any personally identifiable information about you that you may have put on your Amazon public profile page. We will store your MTurk worker ID separately from the other information you provide to us.

You will be compensated with $\$ 3.75$ (U.S.) paid to your Amazon Mechanical Turk account.

Participating in this study is completely voluntary. Even if you decide to participate now, you may change your mind and stop at any time. You may choose not to answer any survey or demographic question for any reason.

If you have questions about this research study, you may contact Christopher J. Holden.

The Appalachian State University Institutional Review Board (IRB) has determined that this study is exempt from IRB oversight.

By selecting to consent to the study, I acknowledge that I am at least 18 years old, have read the above information, and agree to participate. 


\section{Appendix H}

\section{Debriefing Form}

Thank you for completing the study. During this study, you were provided feedback about your personality, and you were told the feedback was based on your responses to the previous questions. However, the feedback provided was false and is in no way an accurate representation of your personality. That is, the feedback did not stem from the responses you provided and was developed by the researchers in an attempt to elicit particular emotional responses. In some cases, this feedback may have been threatening, but please keep in mind that it is entirely false. This manipulation was used in order to determine how people respond to feedback about their relationships and the false nature of the feedback was withheld from you at the start of the study to ensure that it was believable. However, we would like to make you fully aware of this now to ensure there is no undue stress.

If you feel that you have been negatively impacted by the study, please be aware of the many resources you can use. Some examples have been listed below.

1. Contact your local health center

2. Contact nationwide and free hotline services

a. Suicide Hotline: 1-800-273-8255

b. Crisis/Depression Hotline: https://www.crisistextline.org/depression

3. Contact online mental health services

If you have questions regarding the study, please contact Christopher J. Holden at Holdencj@appstate.edu or (828)262-894.

Once you have read the debriefing form, continue to the next page to receive a copy of the consent form and your completion code. 


\section{Appendix I}

Instructional Prompt

Instructions $^{3}$ : You will be asked to respond to a series of questionnaires that address a variety of questions about your personality, as well as behaviors and attitudes that may occur in your relationship. Please consider the time periods specified and provide your most accurate and honest estimate of how frequently each behavior occurs. Also, after completing this measure below, you will receive feedback in regard to your responses.

${ }^{3}$ The prompt will be provided to all participants directly after the consent form and before they begin to answer questions. 
Appendix $\mathbf{J}$

IRB Approval

To: Sierra Rufino

Psychology

CAMPUS EMAIL

From: Dr. Andrew Shanely, IRB Chairperson

Date: October 1, 2019

RE: Notice of IRB Approval by Expedited Review (under 45 CFR 46.110)

STUDY \#: 20-0028

STUDY TITLE: Relationship-Contingent Self-Esteem as a Moderator of Borderline Personality Features and Mate Retention

Submission Type: Initial

Expedited Category: 7.Surveys/interviews/focus groups

Approval Date: 10/01/2019

The Institutional Review Board (IRB) approved this study for the period indicated above. The IRB found that the research procedures meet the expedited category cited above.

IRB approval is limited to the activities described in the IRB approved materials, and extends to the performance of the described activities in the sites identified in the IRB application. In accordance with this approval, IRB findings and approval conditions for the conduct of this research are listed below. 


\section{Vita}

Sierra Maria Rufino was born in Princeton, New Jersey to Douglas and Diane Rufino. She attended the University of North Carolina at Greensboro in 2014 and graduated with full university honors and a bachelor's degree in science for psychology in 2018. Sierra continued her academic career the following autumn at Appalachian State University to earn her Master of Arts degree in experimental psychology. Sierra aims to receive her doctoral degree in clinical psychology. 